\title{
Synthesis and in vitro and in vivo biological evaluation of tissue specific bisthiazole histone deacetylase (HDAC) inhibitors
}

Shu-Wei Zhang, $†, \S$, // Chao-Jun Gong, †, /l Ming-Bo Su, † Fei Chen, $†$ Ting He, † Yang-

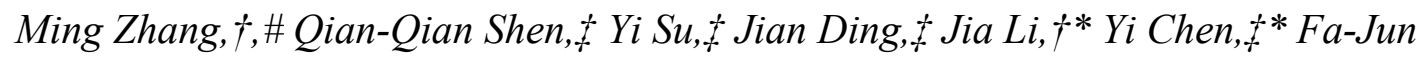

Nan†,\#*

$\uparrow$ State Key Laboratory of Drug Research, the National Center for Drug Screening,

Shanghai Institute of Materia Medica, Chinese Academy of Sciences, Shanghai,

201203, China;

\# Yantai Key Laboratory of Nanomedicine \& Advanced Preparations, Yantai Institute of Materia Medica, Shandong, 264000, China;

$\$$ Division of Antitumor Pharmacology, State Key Laboratory of Drug Research, Shanghai Institute of Materia Medica, Chinese Academy of Sciences, Shanghai 201203, China

$\S$ University of Chinese Academy of Sciences, No.19A Yuquan Road, Beijing, 100049, P. R. China

|| These authors contributed equally

KEYWORDS: Histone deacetylase inhibitors; Bisthiazole; Solid tumor. 


\section{Table of Contents:}

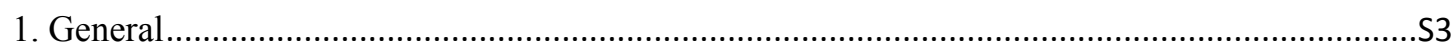

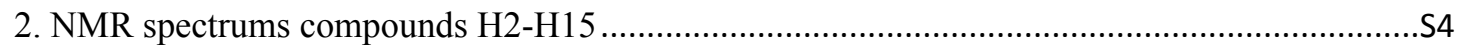

3. The HPLC spectrums of compound H2-15 ……….............................................................

4. Enzymatic assay with recombinant human HDACs .................................................................

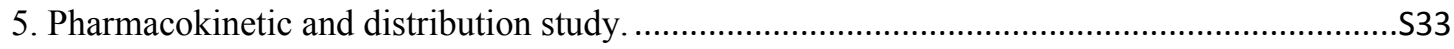

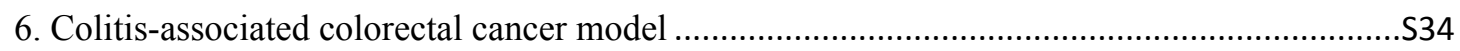

7. Computational modeling/docking studies of H6a and H6b ..................................................S35

8. Compound H13 Metabolic species variability experiment. ....................................................S36 


\section{General}

Starting materials, reagents and solvents were purchased from commercial suppliers and used without further purification. Anhydrous toluene and DCE were obtained from a distillation over sodium wire or $\mathrm{CaH}_{2}$. All non-aqueous reactions were run under an inert atmosphere (nitrogen or argon) with rigid exclusion of moisture from reagents and all reaction vessels were oven-dried. Thin-layer chromatography (TLC) was carried out on pre-coated TLC plates with silica gel HSGF 254. Spots were visualized under UV at $254 \mathrm{~nm} .{ }^{1} \mathrm{H}-\mathrm{NMR}$ and ${ }^{13} \mathrm{C}-\mathrm{NMR}$ spectra were measured on a Varian Mercury-VX 300, Varian MR 400, AVANCE III 500 or AVANCE III 600 spectrometer using deuterated chloroform $\left(\mathrm{CDCl}_{3}\right)$, deuterated methanol $\left(\mathrm{CD}_{3} \mathrm{OD}\right)$, deuterated acetone (acetone- $\mathrm{d}_{6}$ ) and deuterated dimethyl sulfoxide (DMSO- $d_{6}$ ) as the solvent. Chemical shifts are expressed in $\delta$ (ppm.). Abbreviations for signal coupling are as follows: s, singlet; brs, broad singlet; d, doublet; t, triplet; q, quartet; dd, double doublet; m, multiplet. Coupling constants $(J)$ are given in Hz. HR-MS were measured on a Micromass Ultra Q-Tof. Purity was evaluated by analytical HPLC chromatograms using Agilent 1200 series LC system equipped with a degasser, a quaternary pump, an auto sampler, a column oven and a diode array detector. Analytes were separated on a Zorbax SB C18 column $(4.6 \times 150 \mathrm{~mm}, 5 \mu \mathrm{m})$. Solvent A was $0.1 \%$ trifluoroacetic acid in $\mathrm{H}_{2} \mathrm{O}$, and solvent B was $100 \%$ methanol. Gradient elution: $20 \%$ B for 2 min, then $20 \%-80 \%$ B from 2 to $20 \mathrm{~min}, 80 \%$ B was maintained for $5 \mathrm{~min}$, then $80 \%-20 \% \mathrm{~B}$ from $25 \mathrm{~min}$ to $30 \mathrm{~min}$. All compounds were monitored at $254 \mathrm{~nm}$ at room temperature. Flow rate: $1.0 \mathrm{~mL} / \mathrm{min}$. The following abbreviations for solvents and reagents are used; $\mathrm{N}$, N-dimethlformamide (DMF), dimethylsulfoxide (DMSO), sodium hydroxide $(\mathrm{NaOH})$, 1,2-dichloroethane (DCE), tetrahydrofuran (THF). 


\section{NMR spectrums compounds H2-H15}

${ }^{1} \mathrm{H}$ NMR of compound $\mathrm{H} 2$

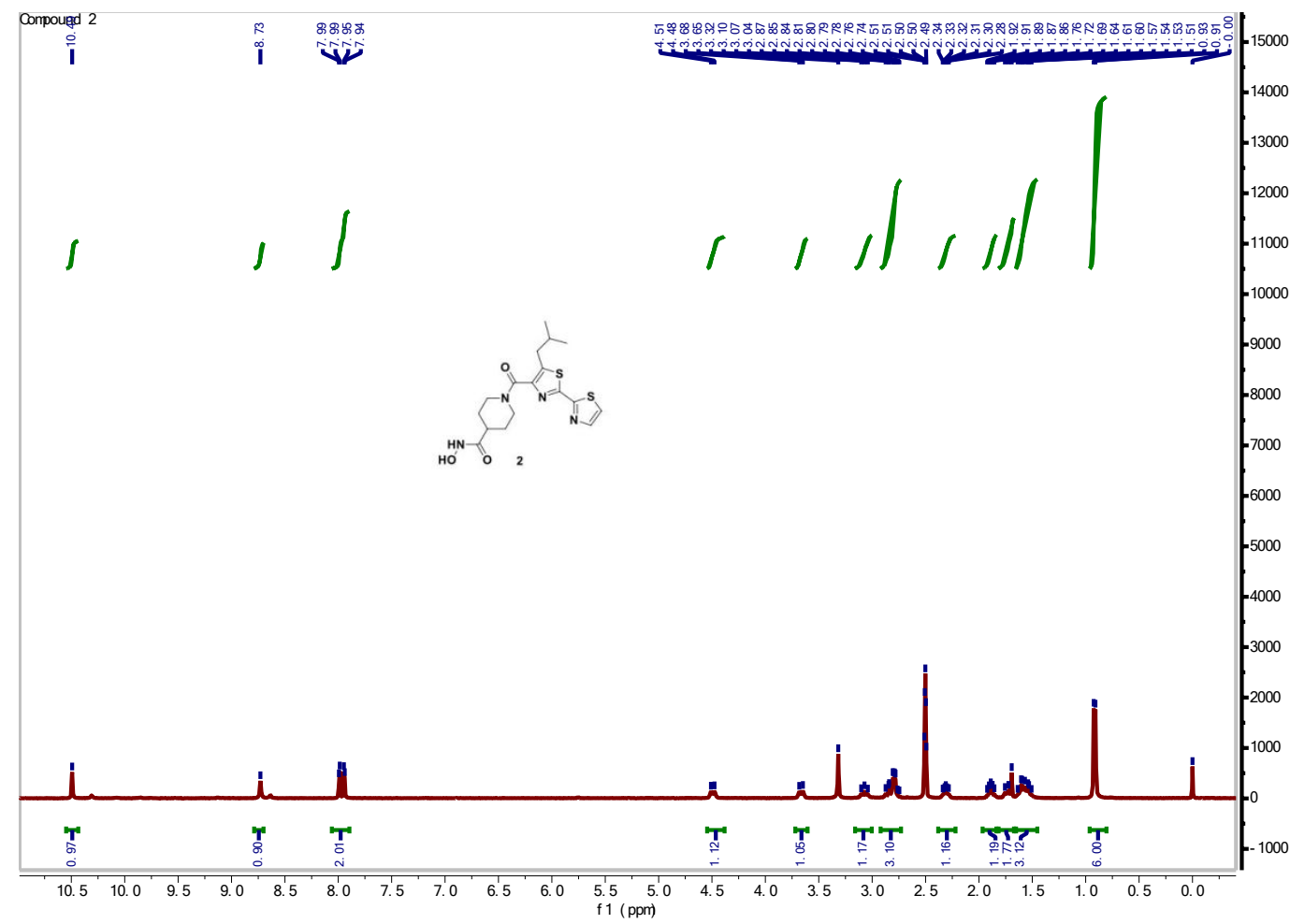

${ }^{13} \mathrm{C}$ NMR of compound $\mathrm{H} 2$

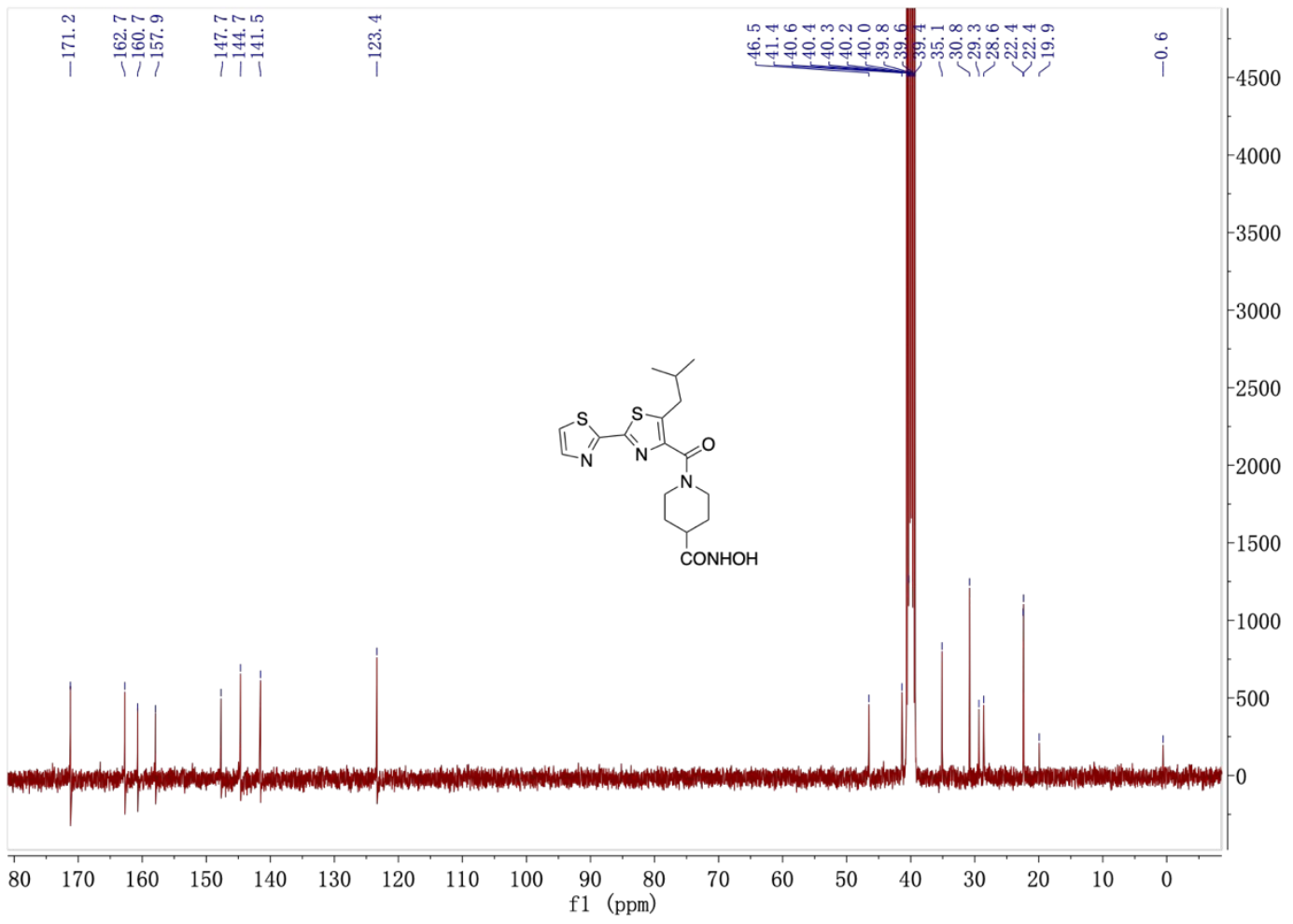


${ }^{1} \mathrm{H}$ NMR of compound H3

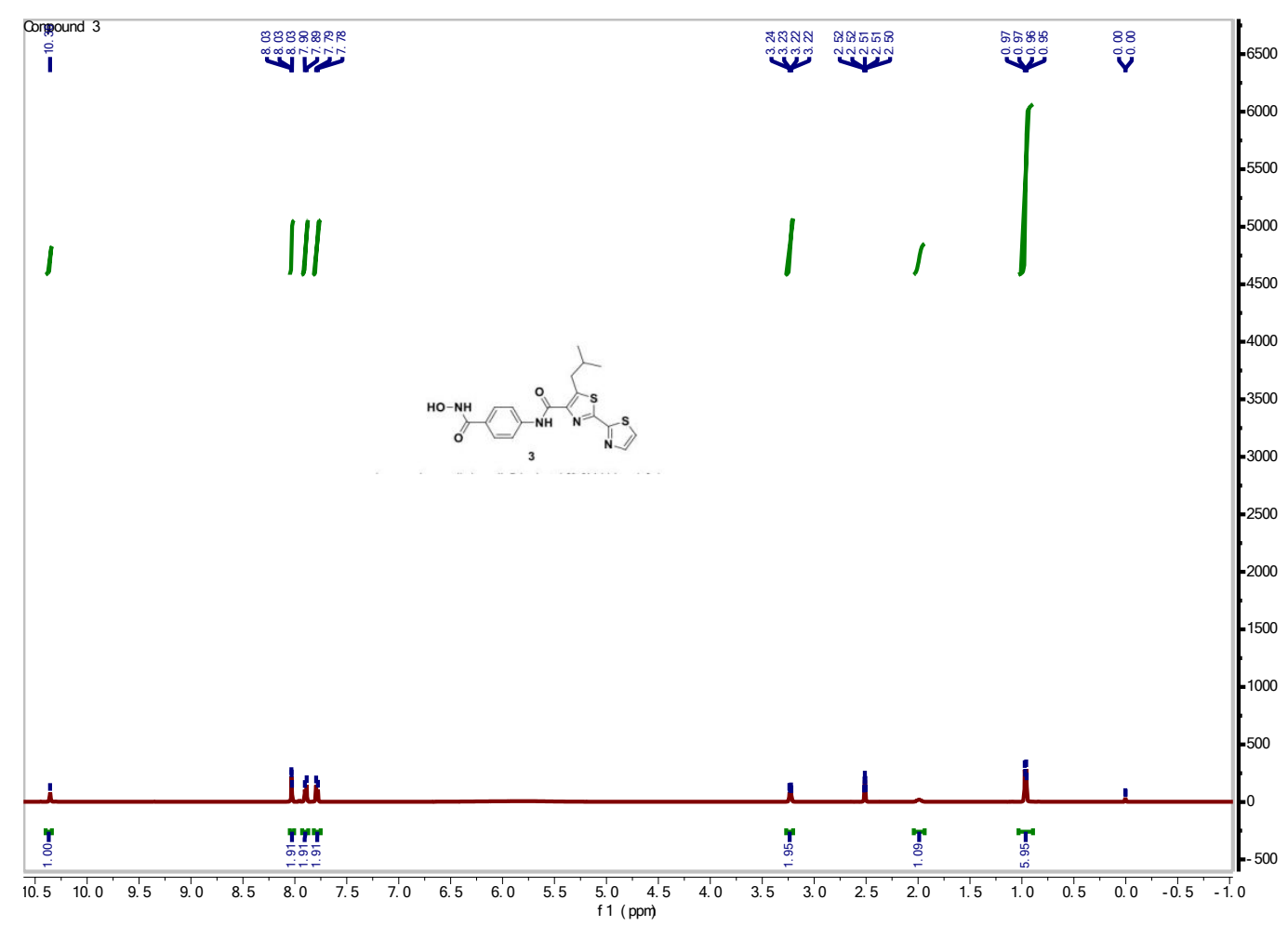

${ }^{13} \mathrm{C}$ NMR of compound $\mathrm{H} 3$

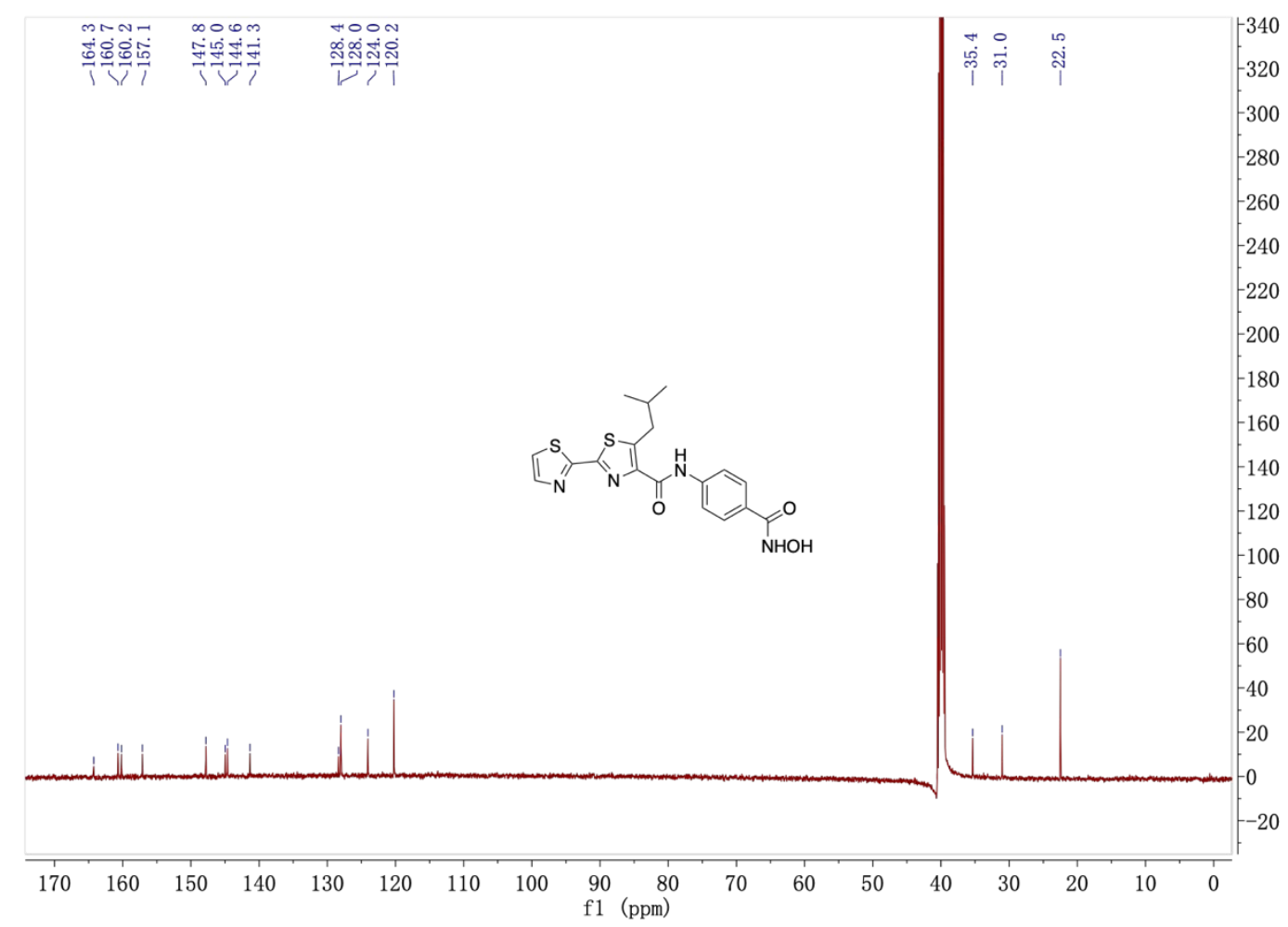


${ }^{1} \mathrm{H}$ NMR of compound H4

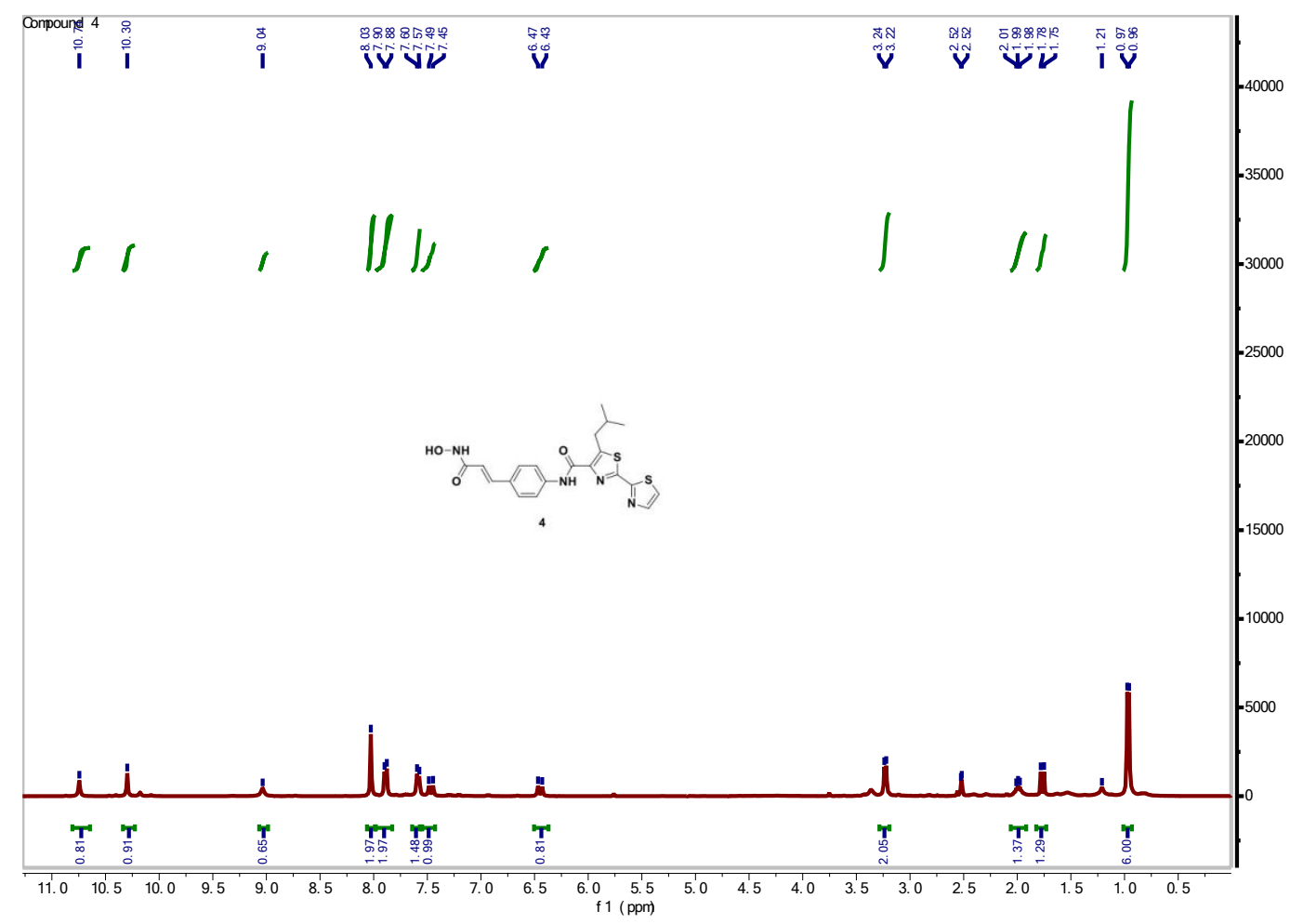

${ }^{13} \mathrm{C}$ NMR of compound $\mathrm{H} 4$

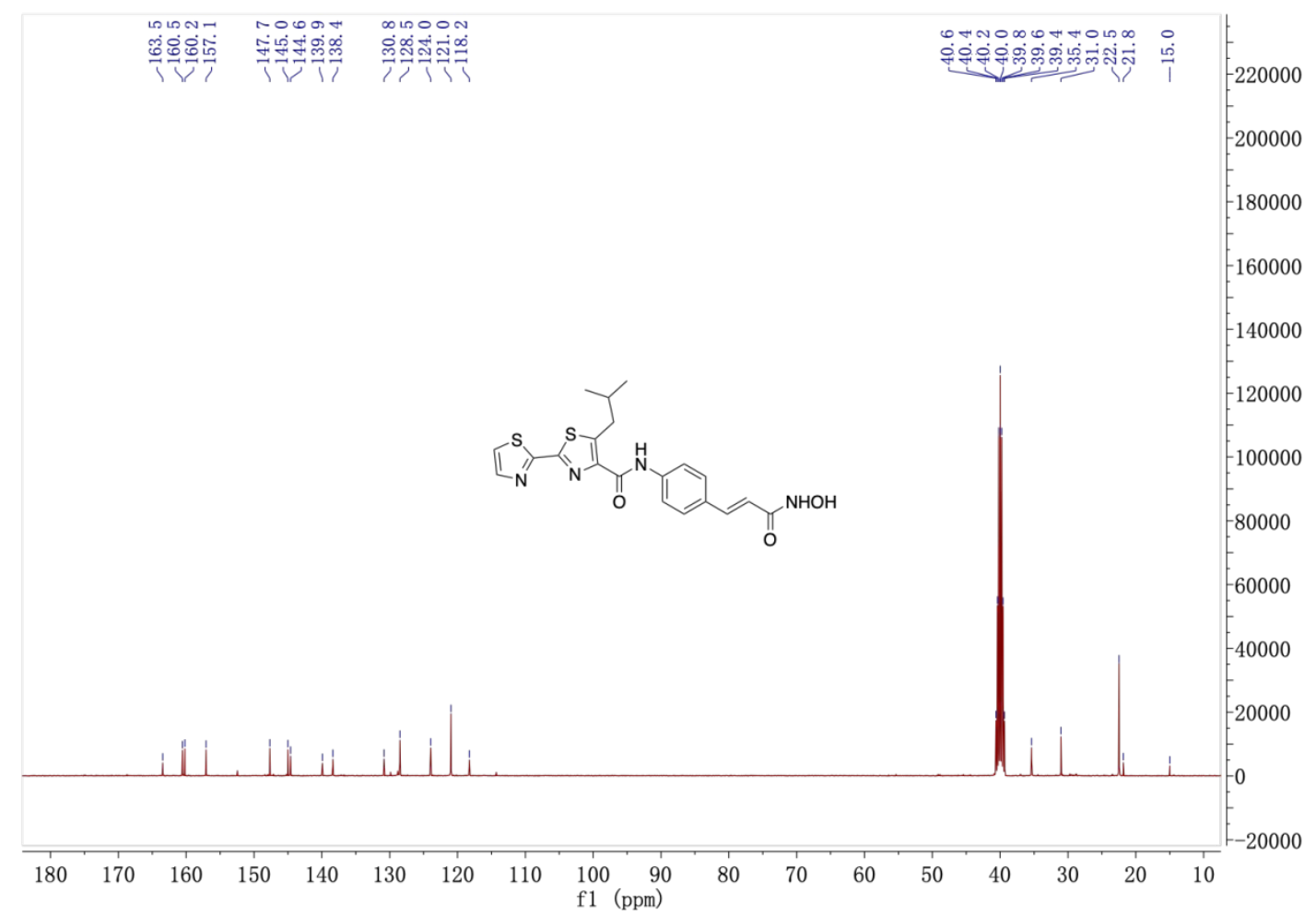


${ }^{1} \mathrm{H}$ NMR of compound H5

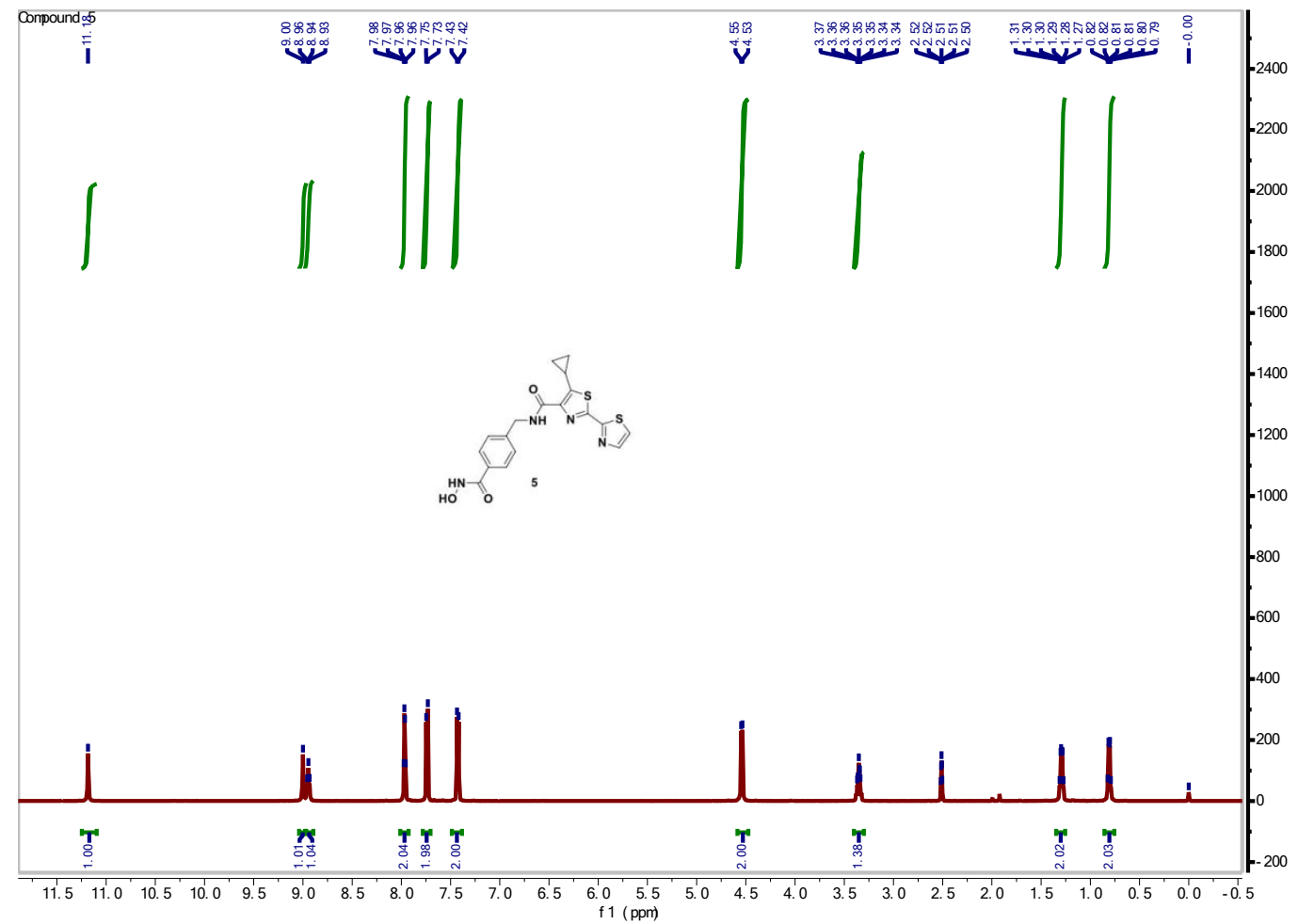

${ }^{13} \mathrm{C}$ NMR of compound $\mathrm{H} 5$

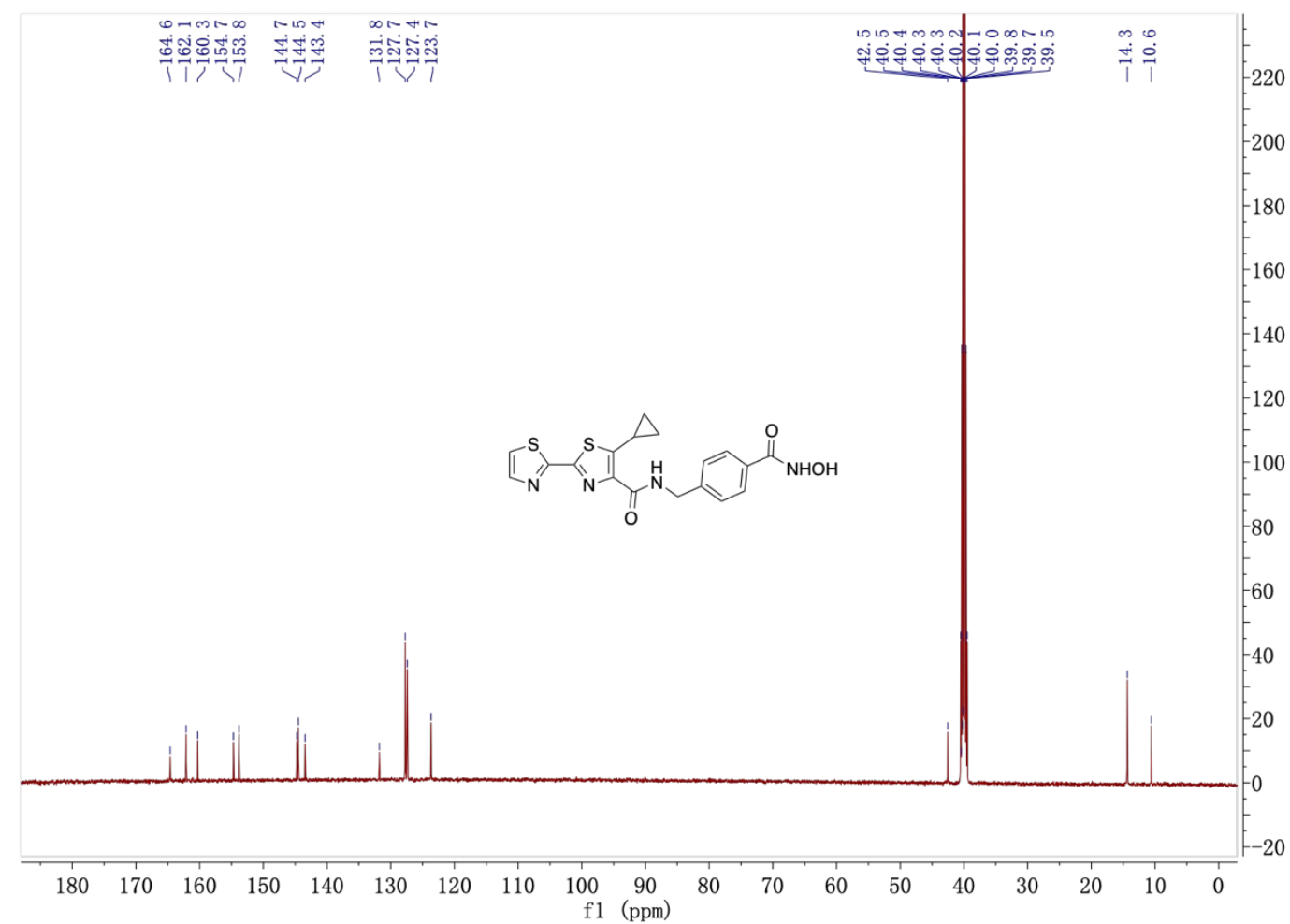


${ }^{1} \mathrm{H}$ NMR of compound H6

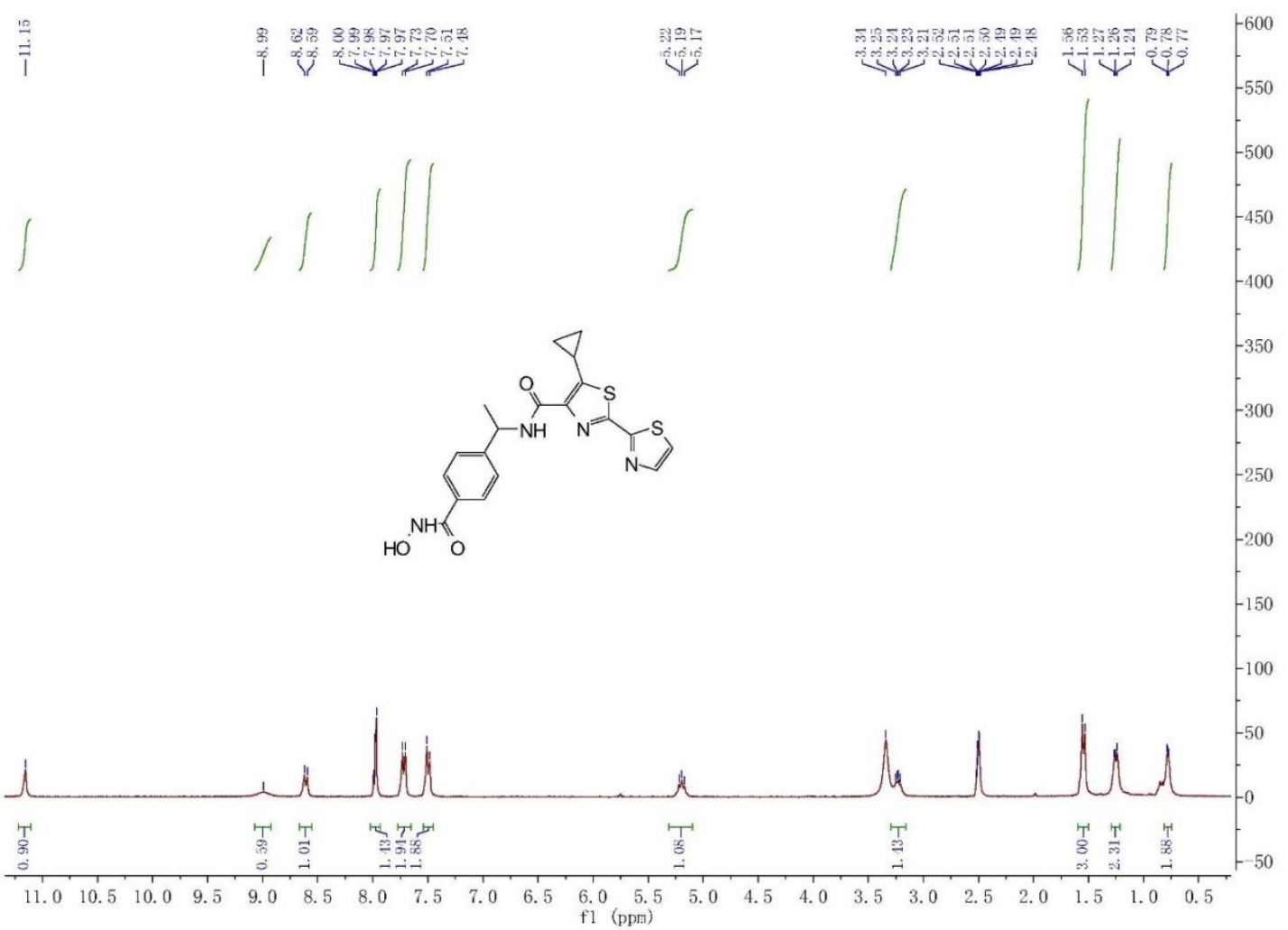

${ }^{1} \mathrm{H}$ NMR of compound H6a

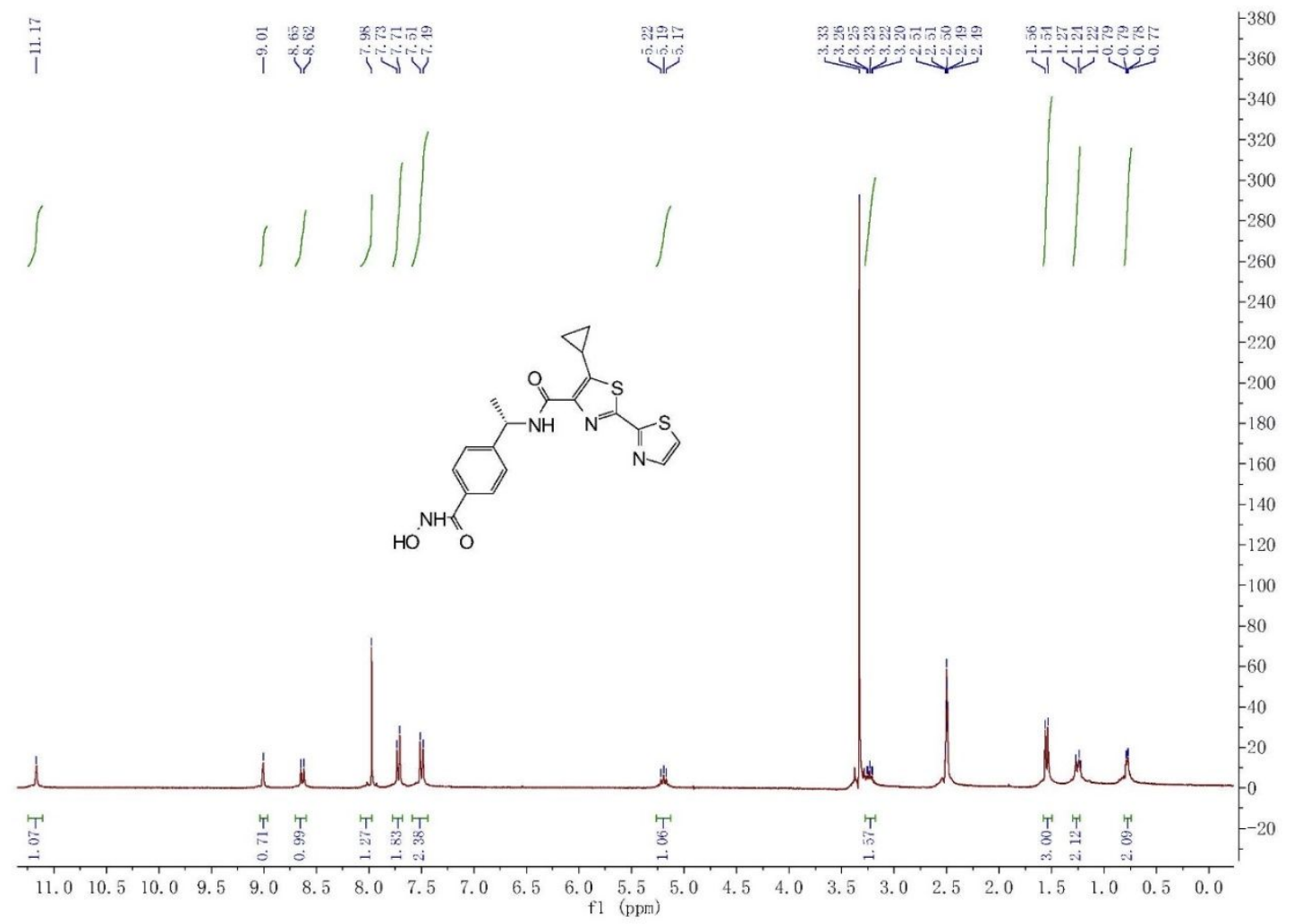


${ }^{1} \mathrm{H}$ NMR of compound H6b

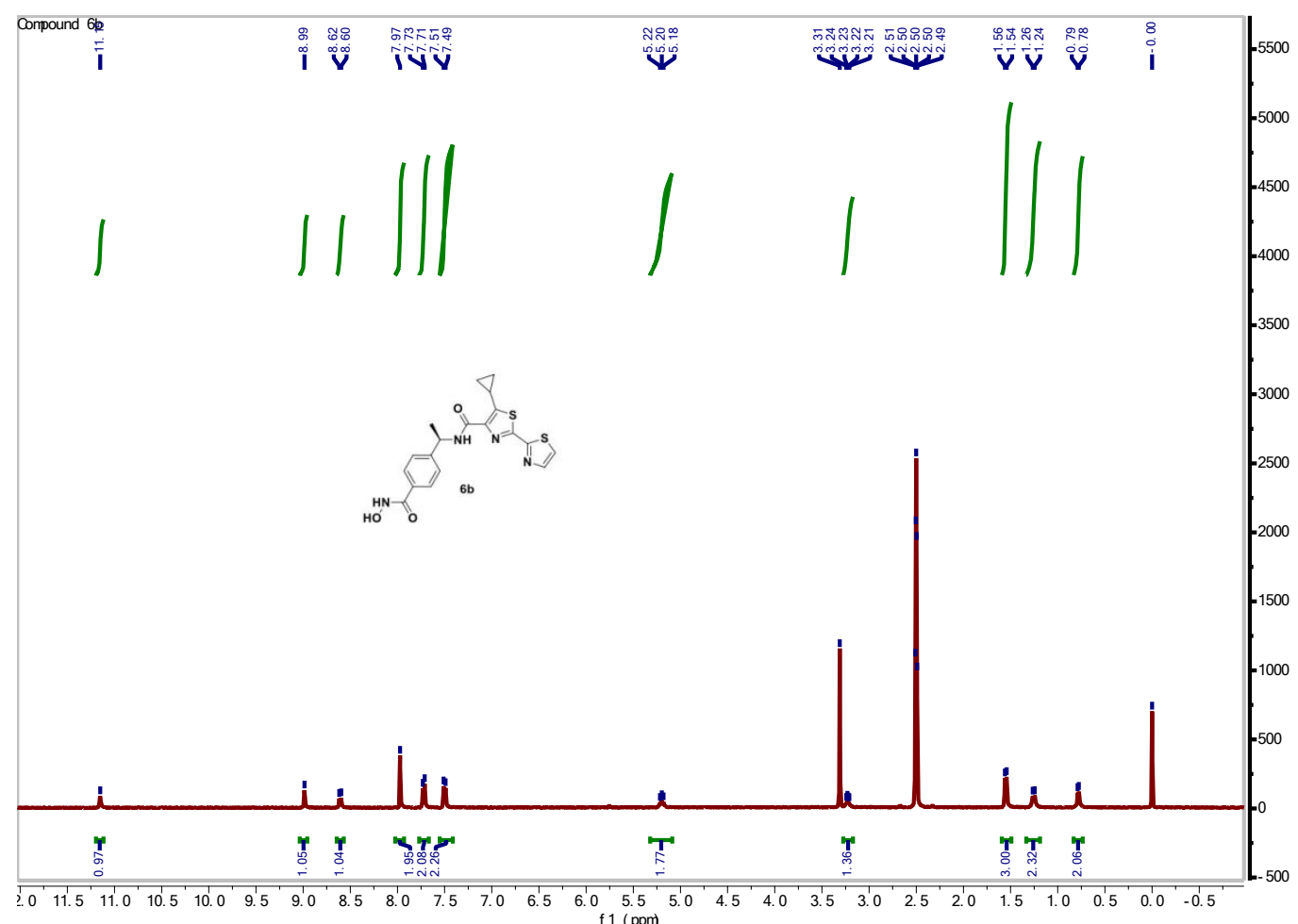

${ }^{13} \mathrm{C}$ NMR of compound $\mathrm{H} 6 \mathrm{~b}$

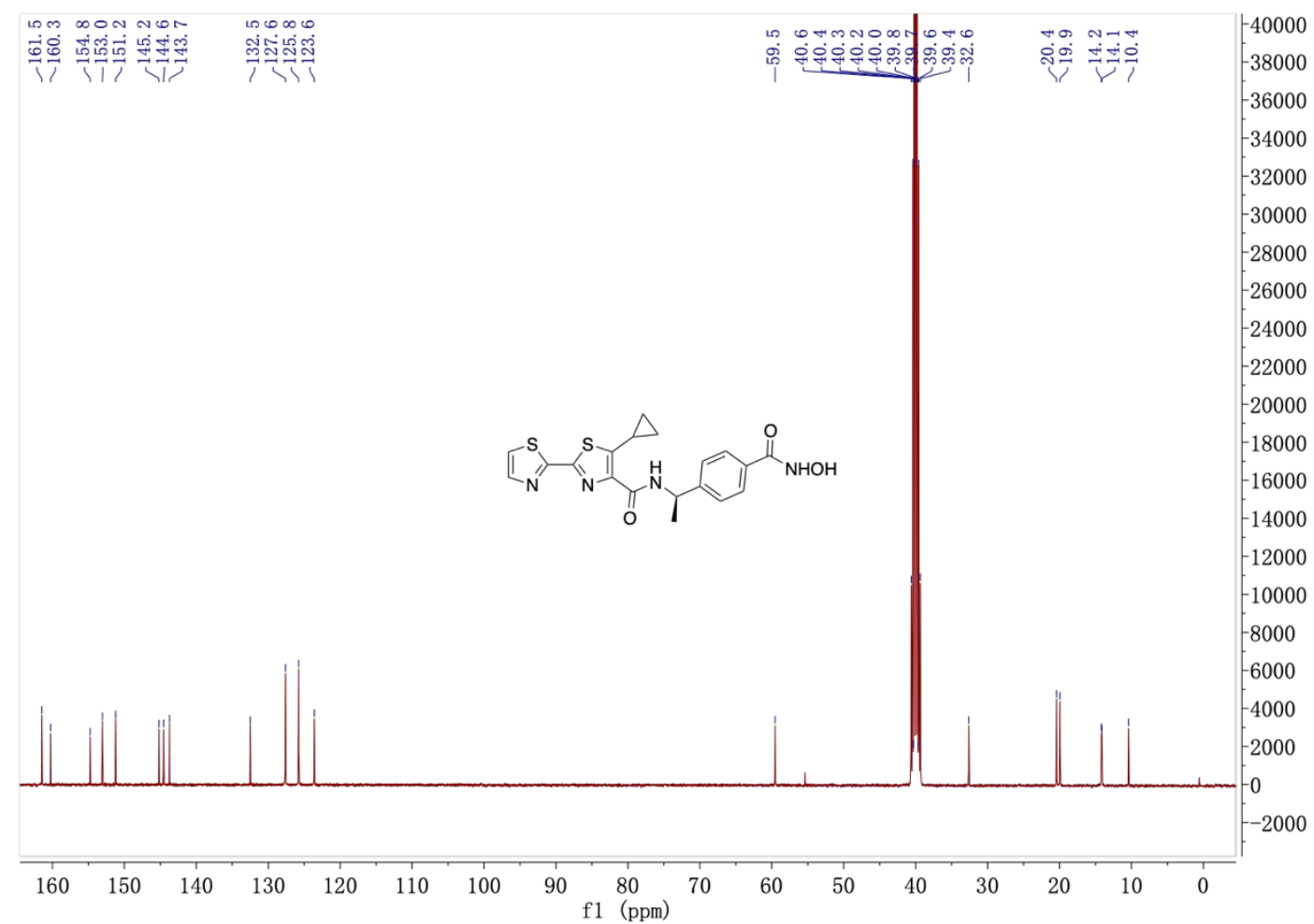


${ }^{1} \mathrm{H}$ NMR of compound H7

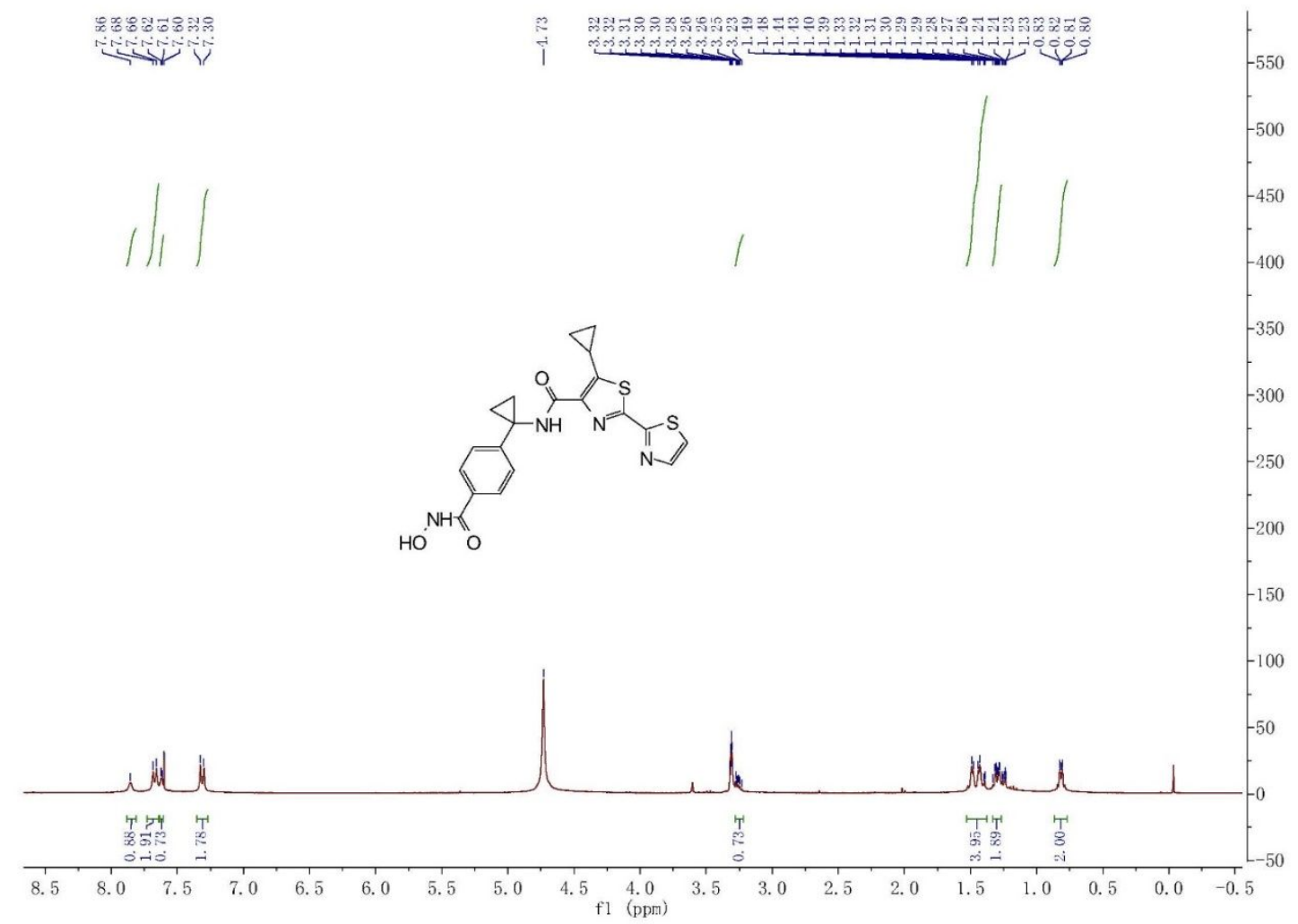

${ }^{13} \mathrm{C}$ NMR of compound $\mathrm{H} 7$

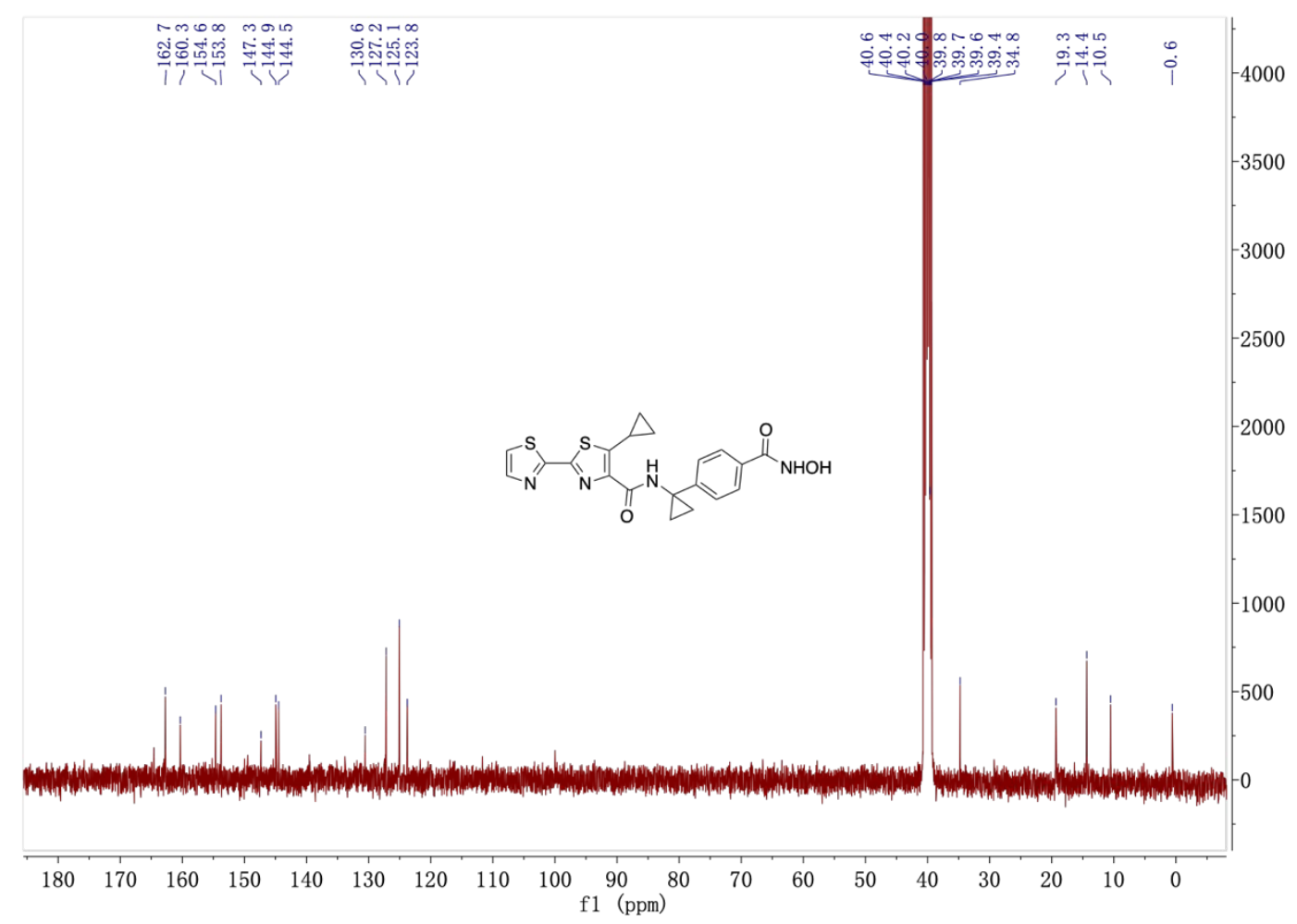


${ }^{1} \mathrm{H}$ NMR of compound $\mathrm{H} 8$

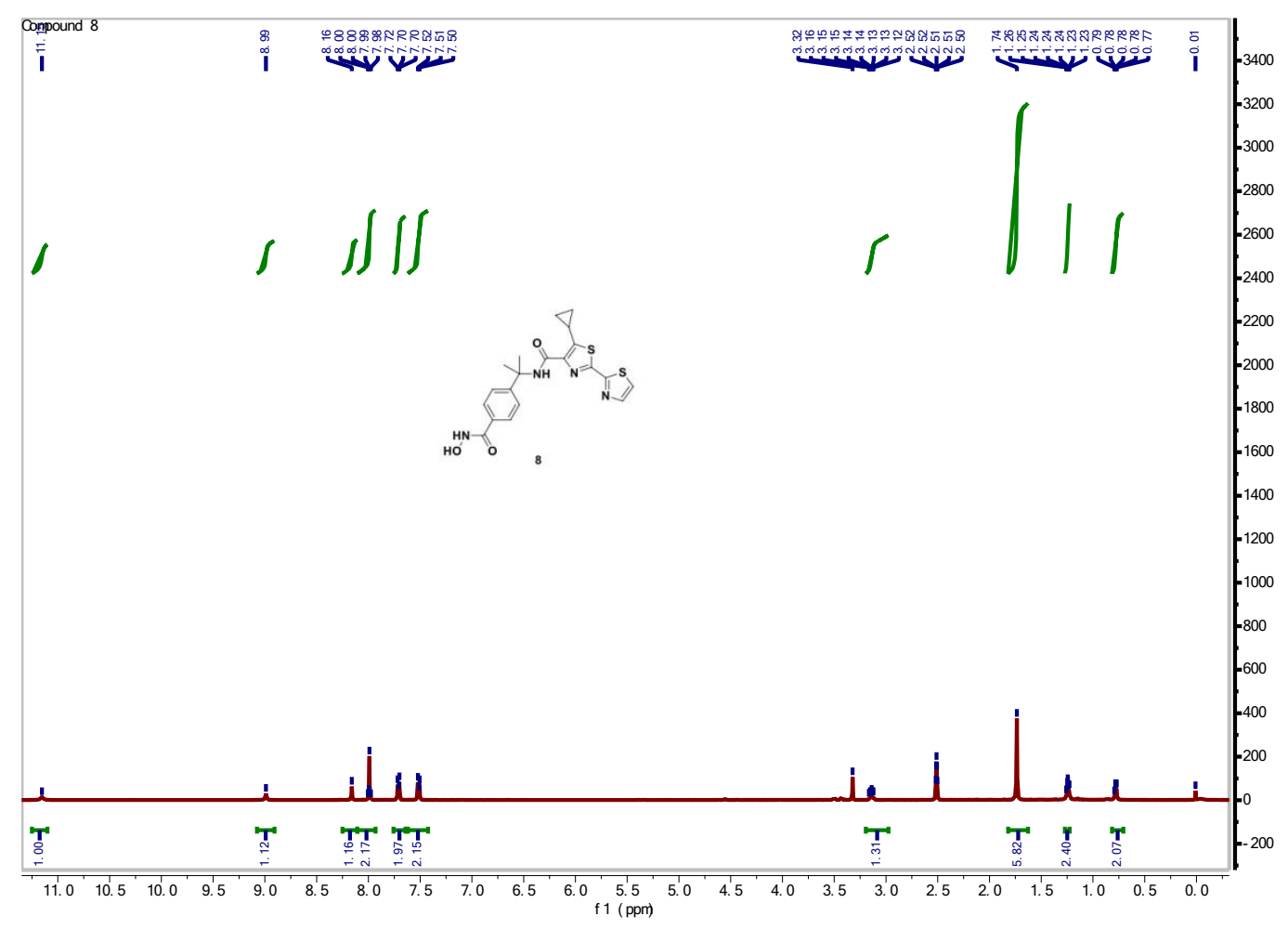

${ }^{13} \mathrm{C}$ NMR of compound $\mathrm{H} 8$

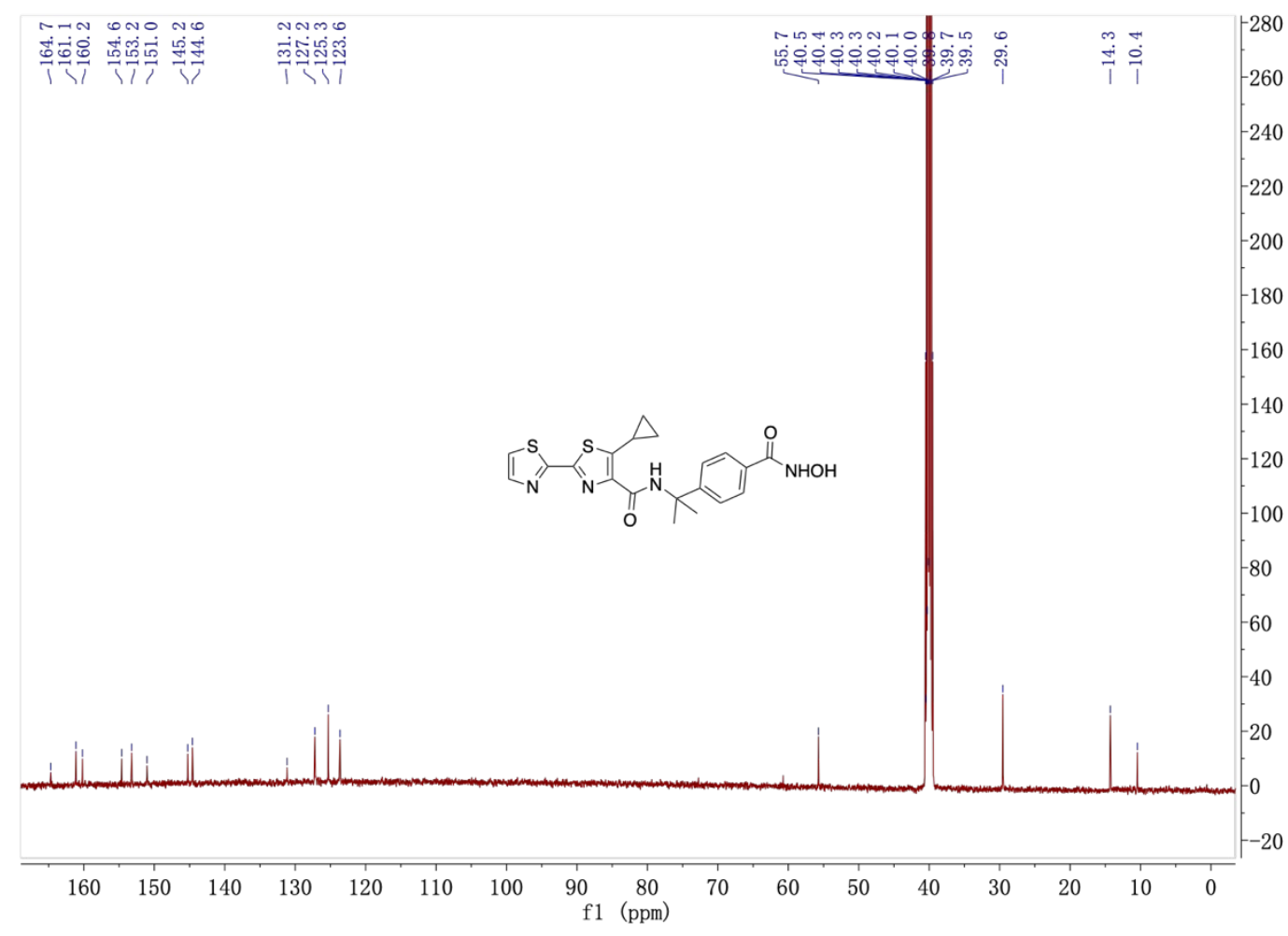


${ }^{1} \mathrm{H}$ NMR of compound H9

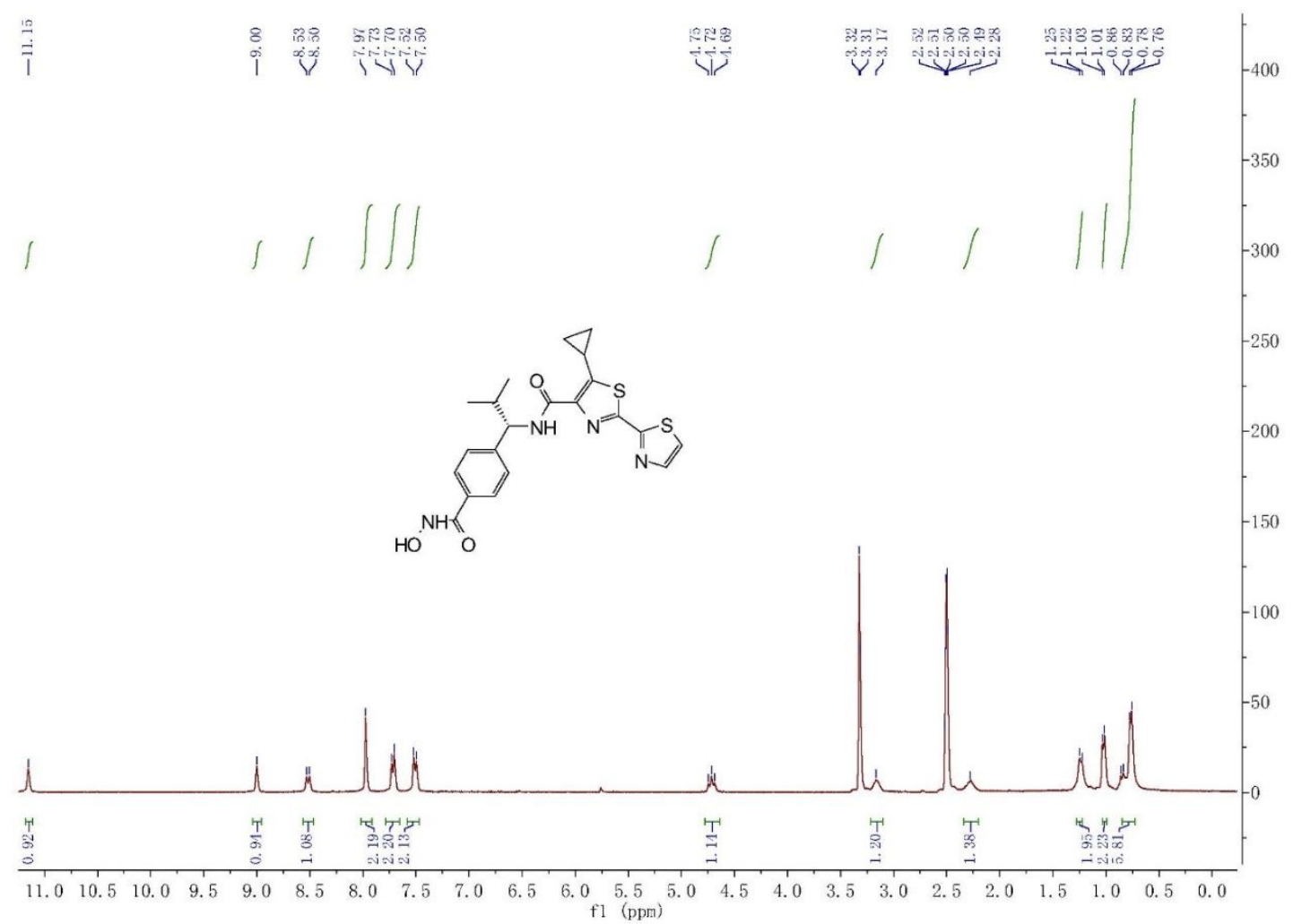

${ }^{13} \mathrm{C}$ NMR of compound $\mathrm{H} 9$

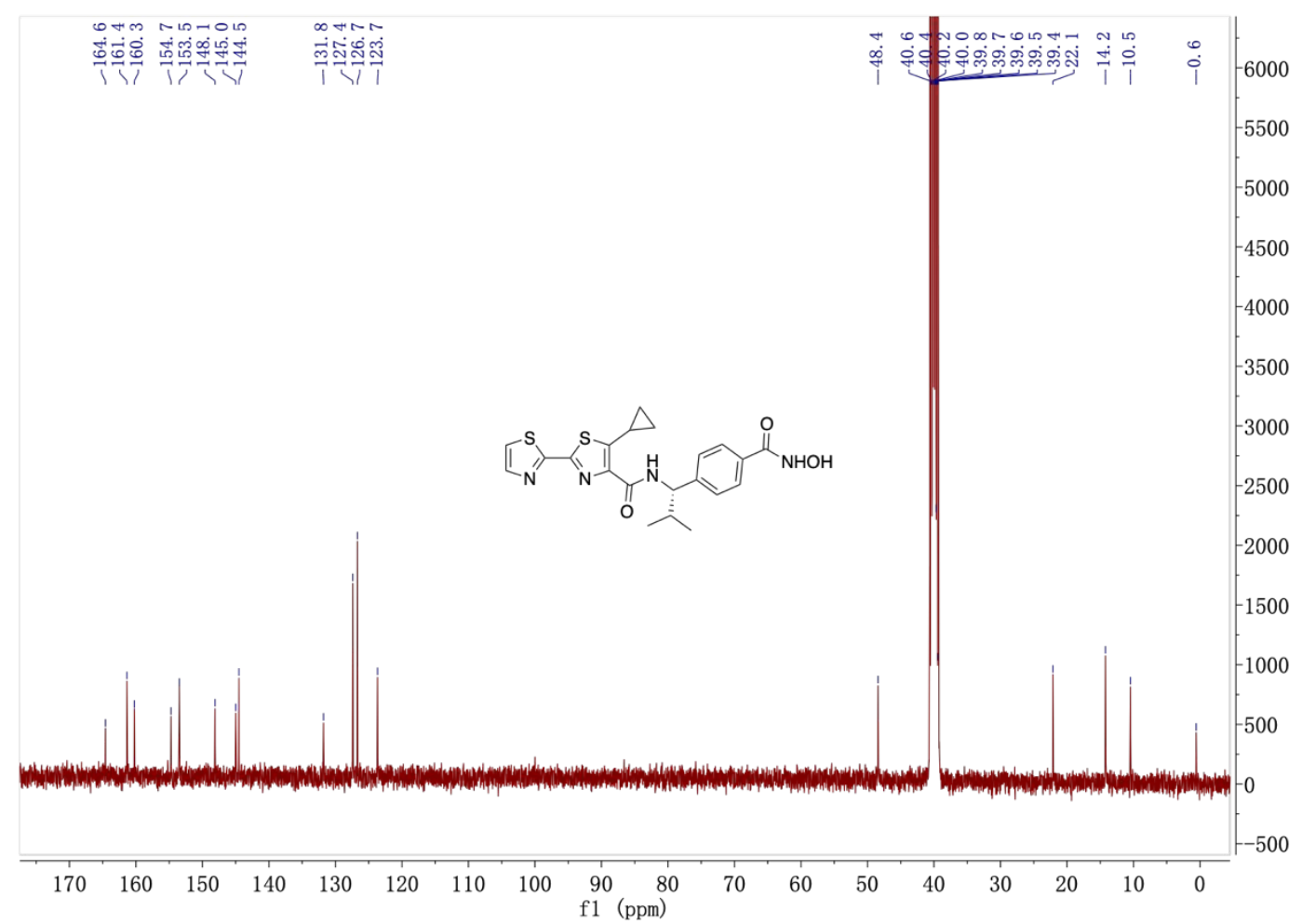


${ }^{1} \mathrm{H}$ NMR of compound H10

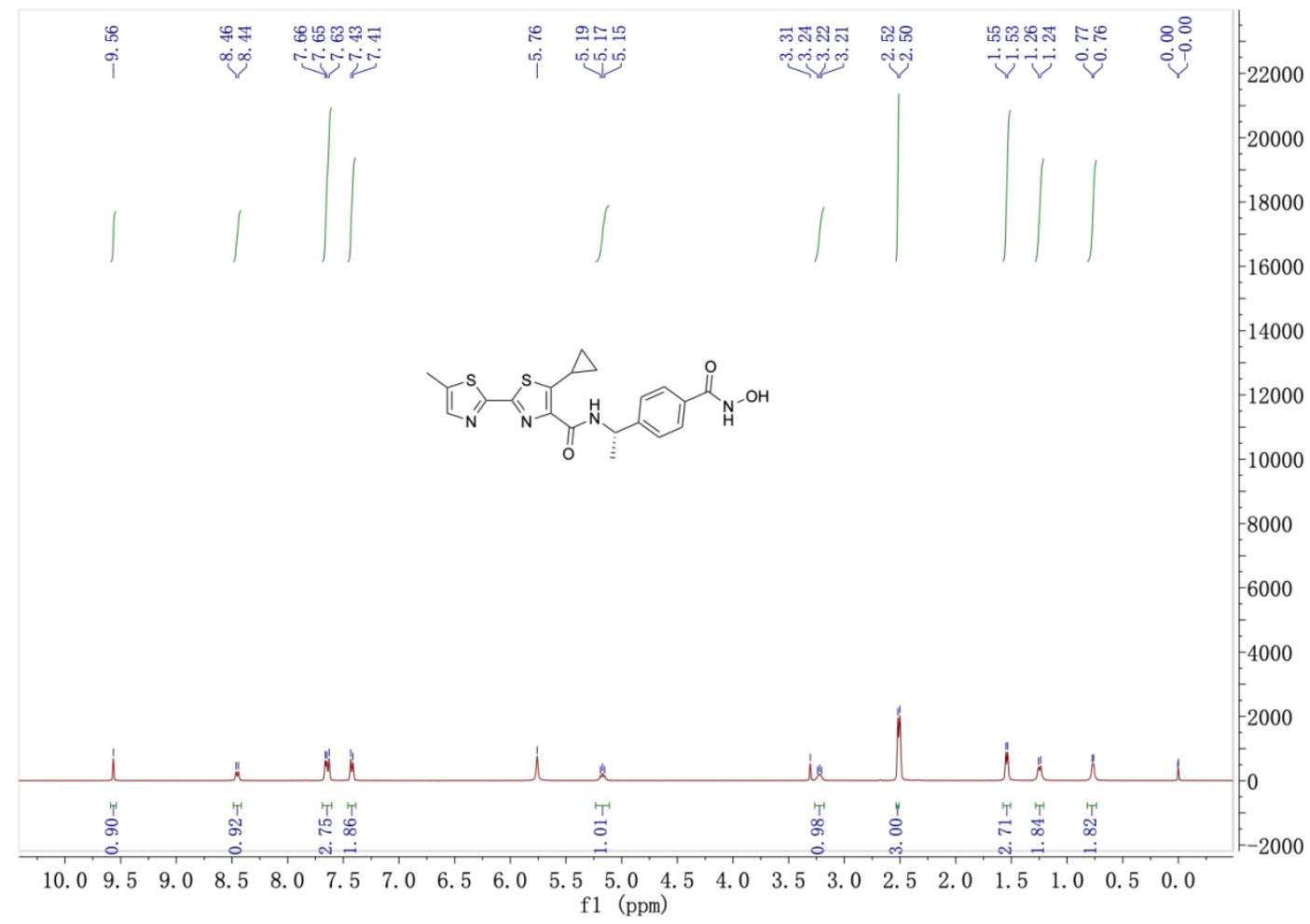

${ }^{13} \mathrm{C}$ NMR of compound H10

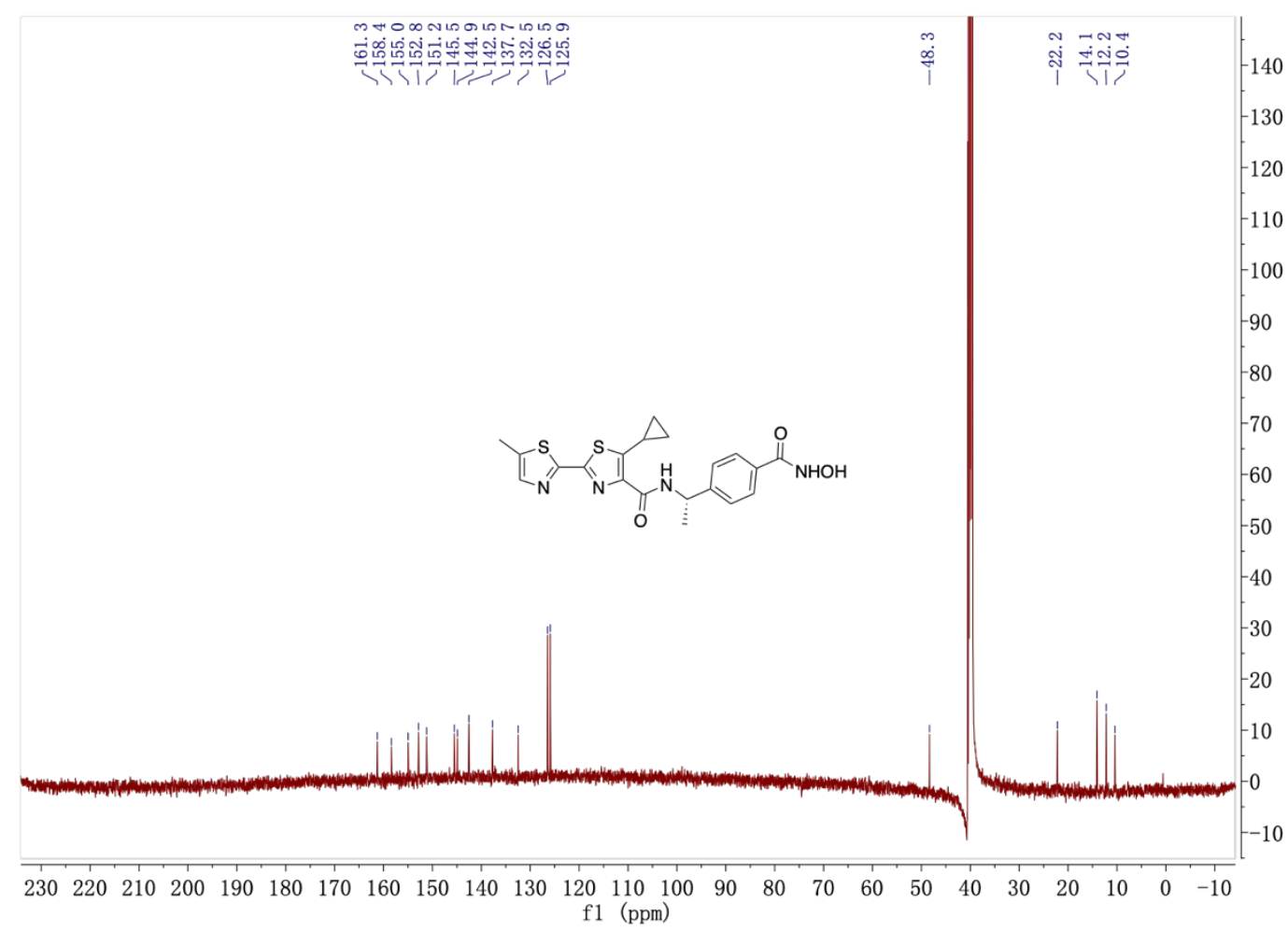


${ }^{1} \mathrm{H}$ NMR of compound H1 1

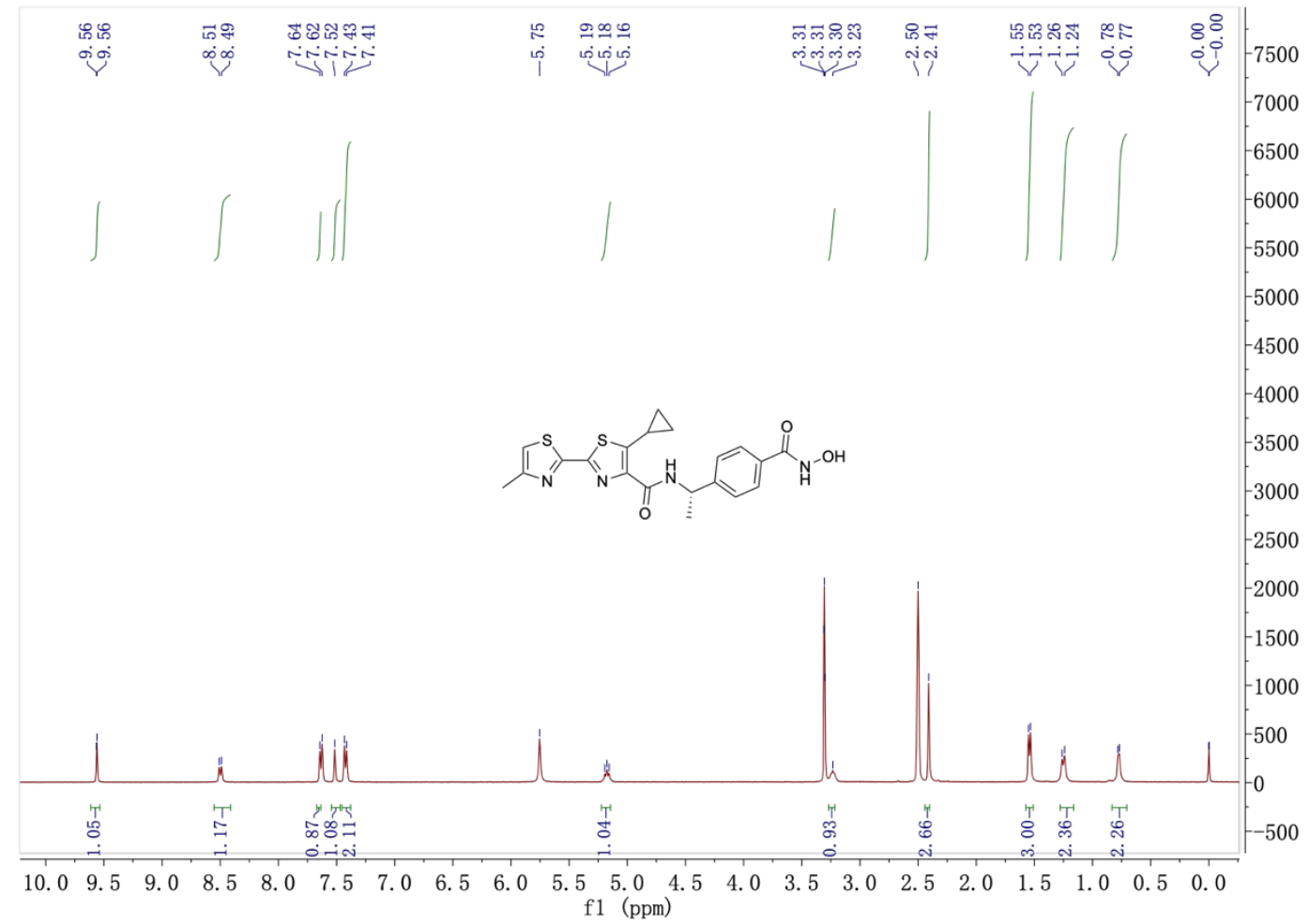

${ }^{13} \mathrm{C}$ NMR of compound H11

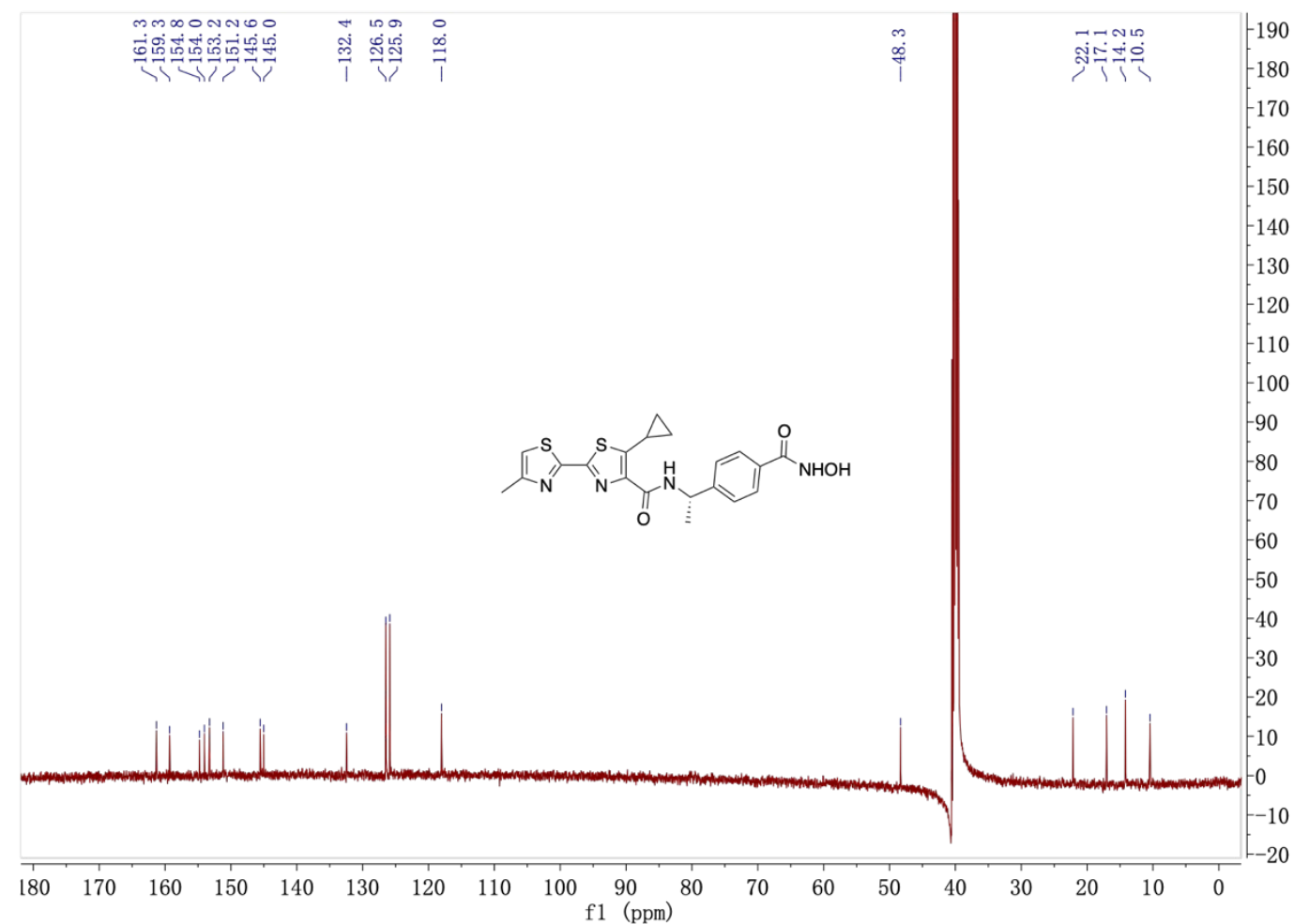


${ }^{1} \mathrm{H}$ NMR of compound H12

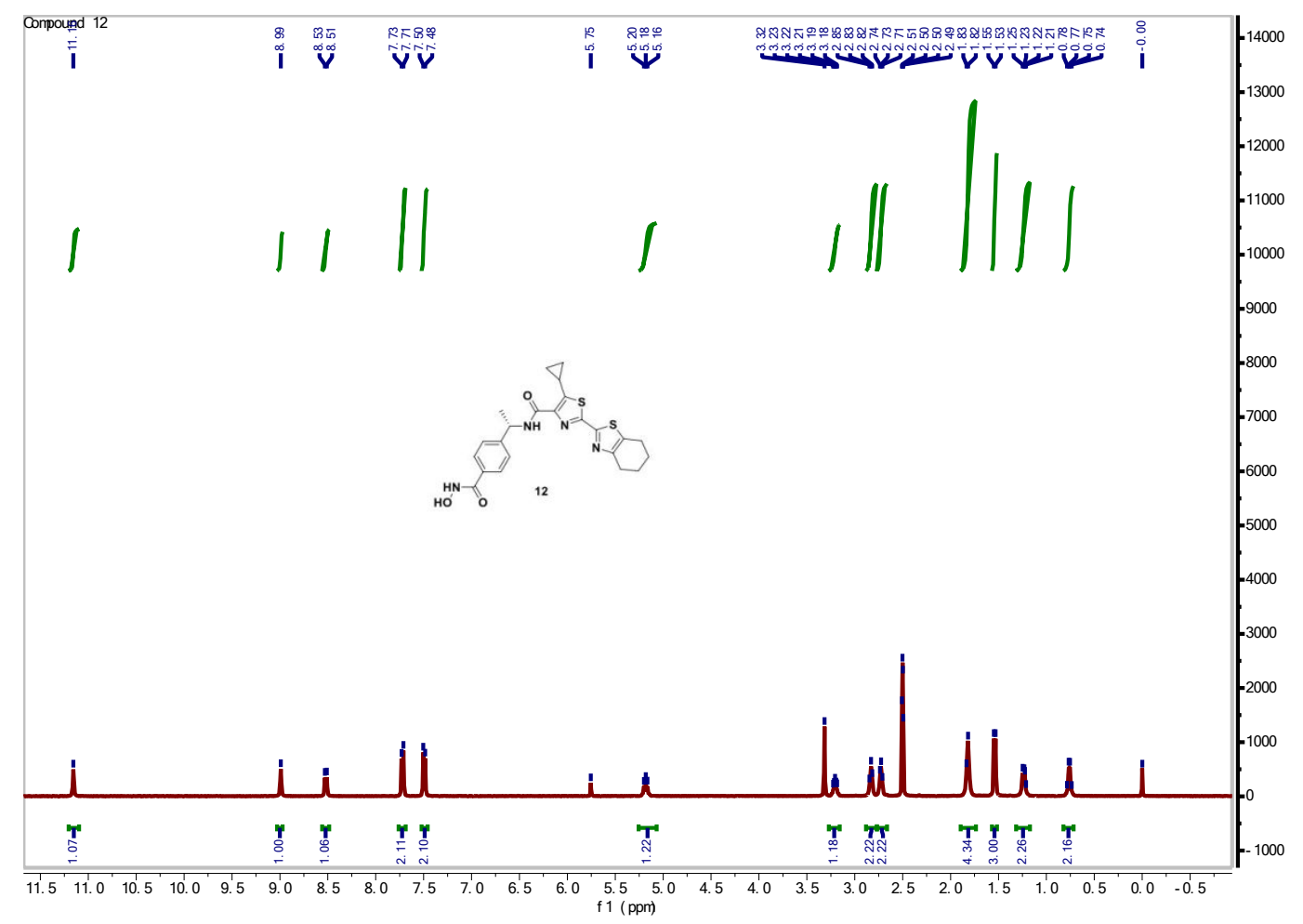

${ }^{13} \mathrm{C}$ NMR of compound H12

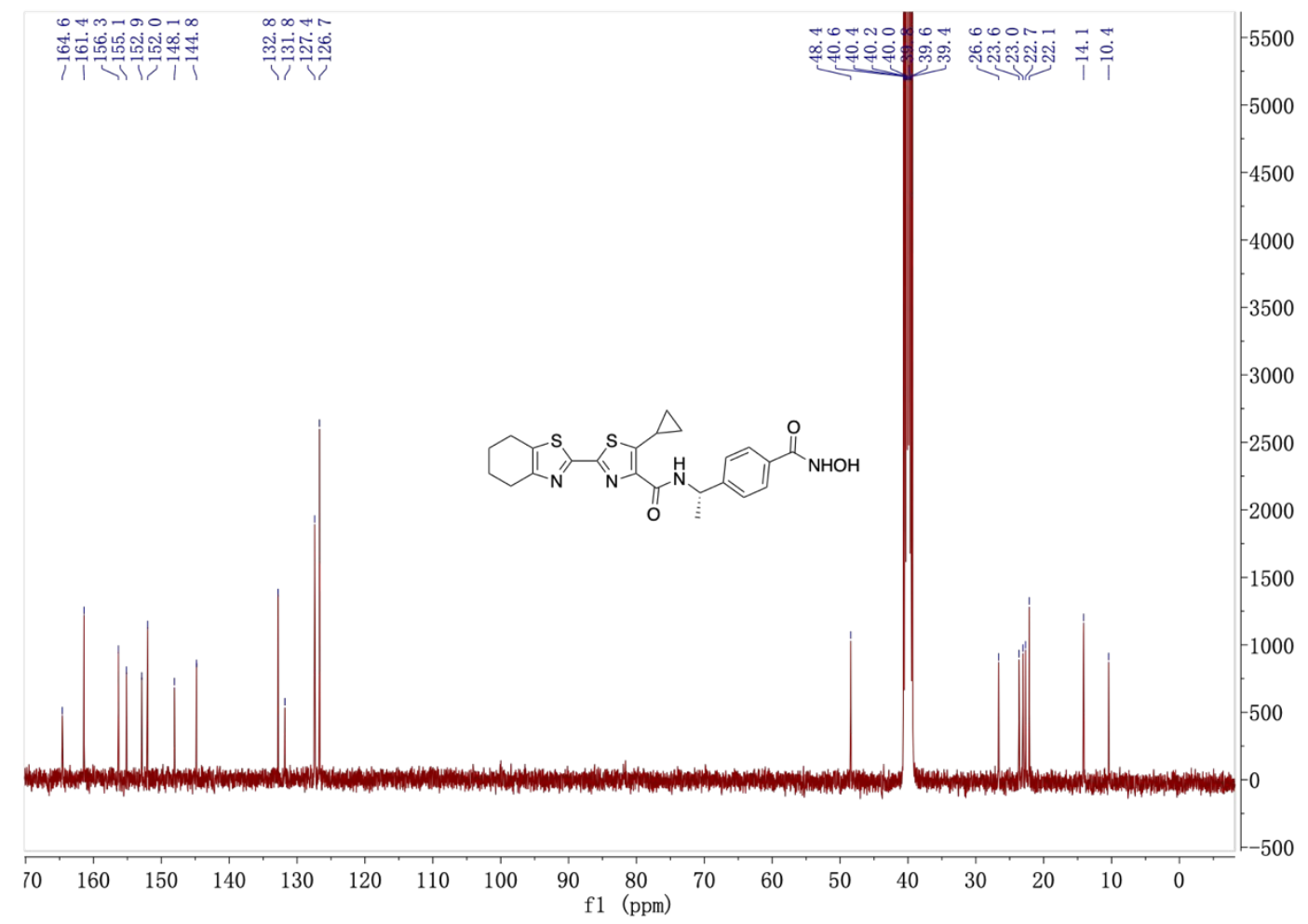




\section{${ }^{1} \mathrm{H}$ NMR of compound H13}

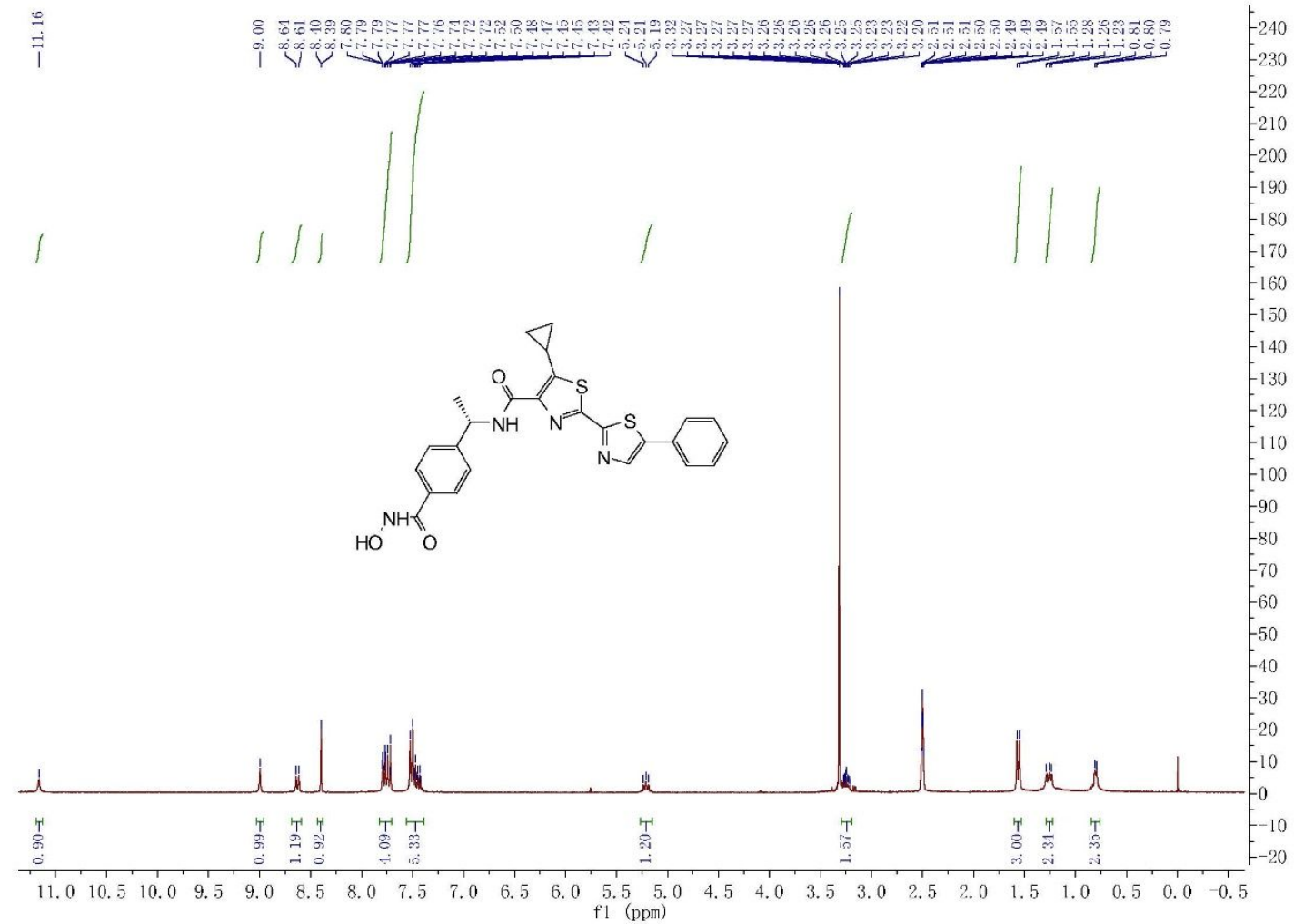

${ }^{13} \mathrm{C}$ NMR of compound H13

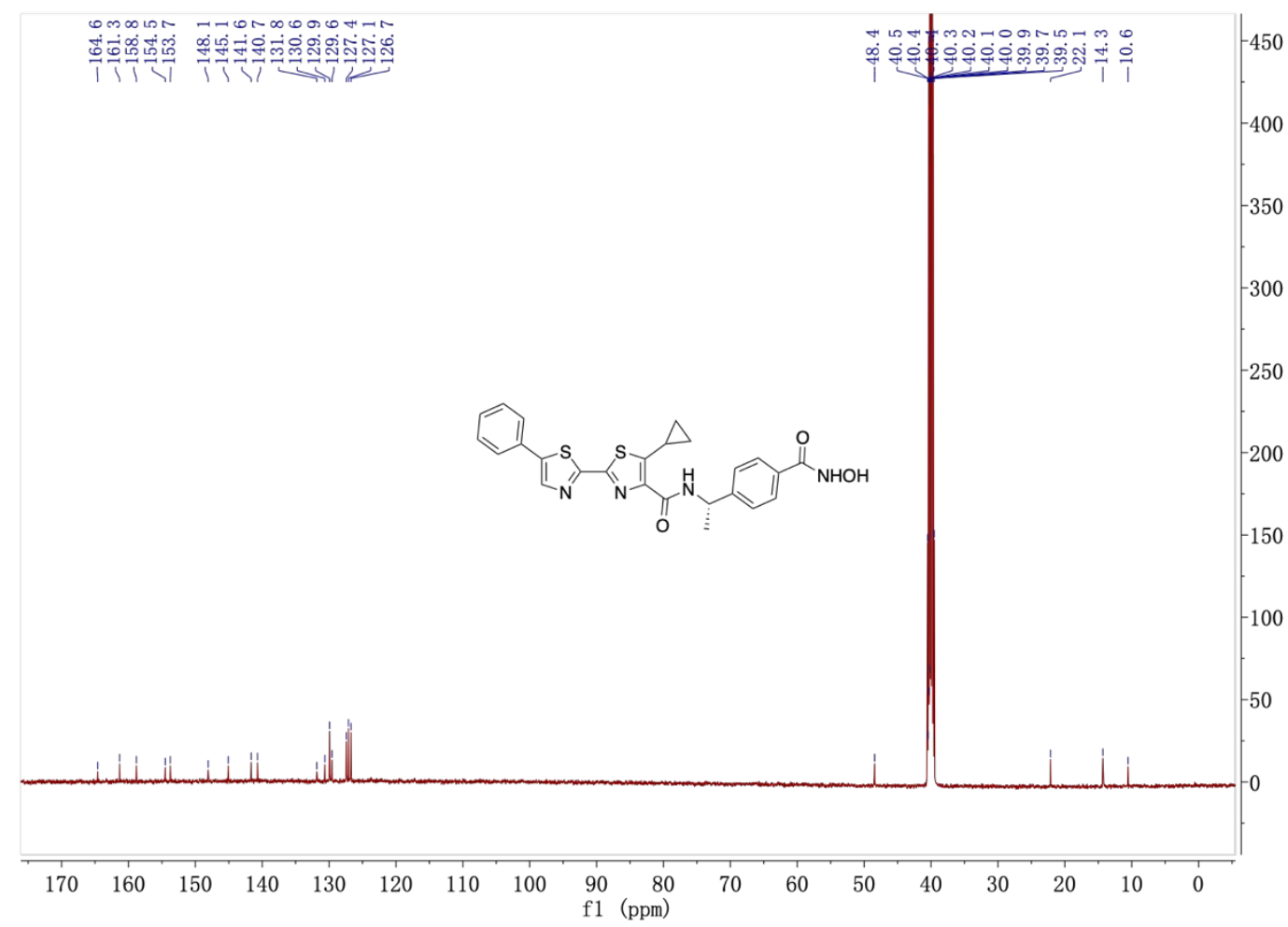


${ }^{1} \mathrm{H}$ NMR of compound H14

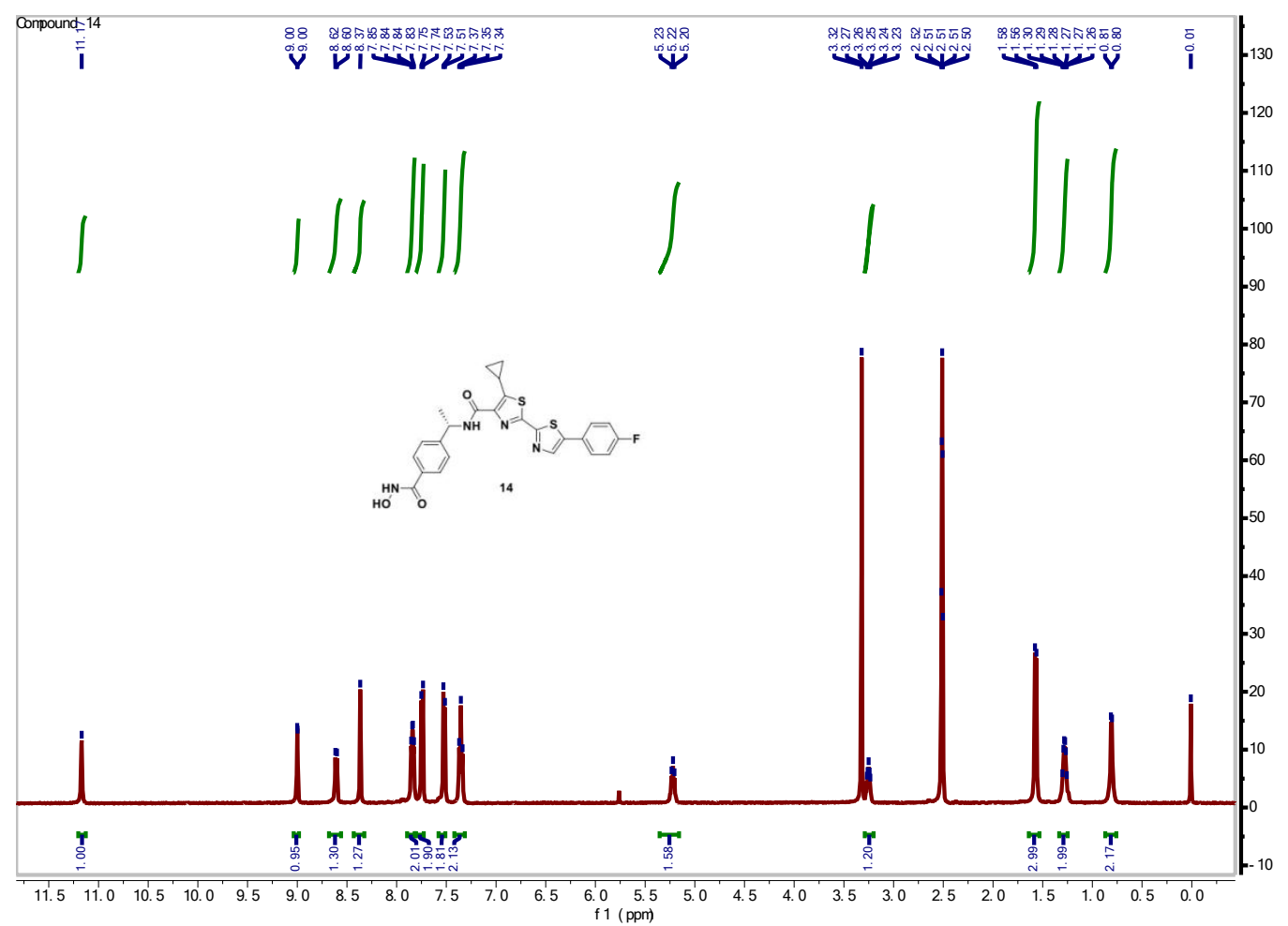

${ }^{13} \mathrm{C}$ NMR of compound H14

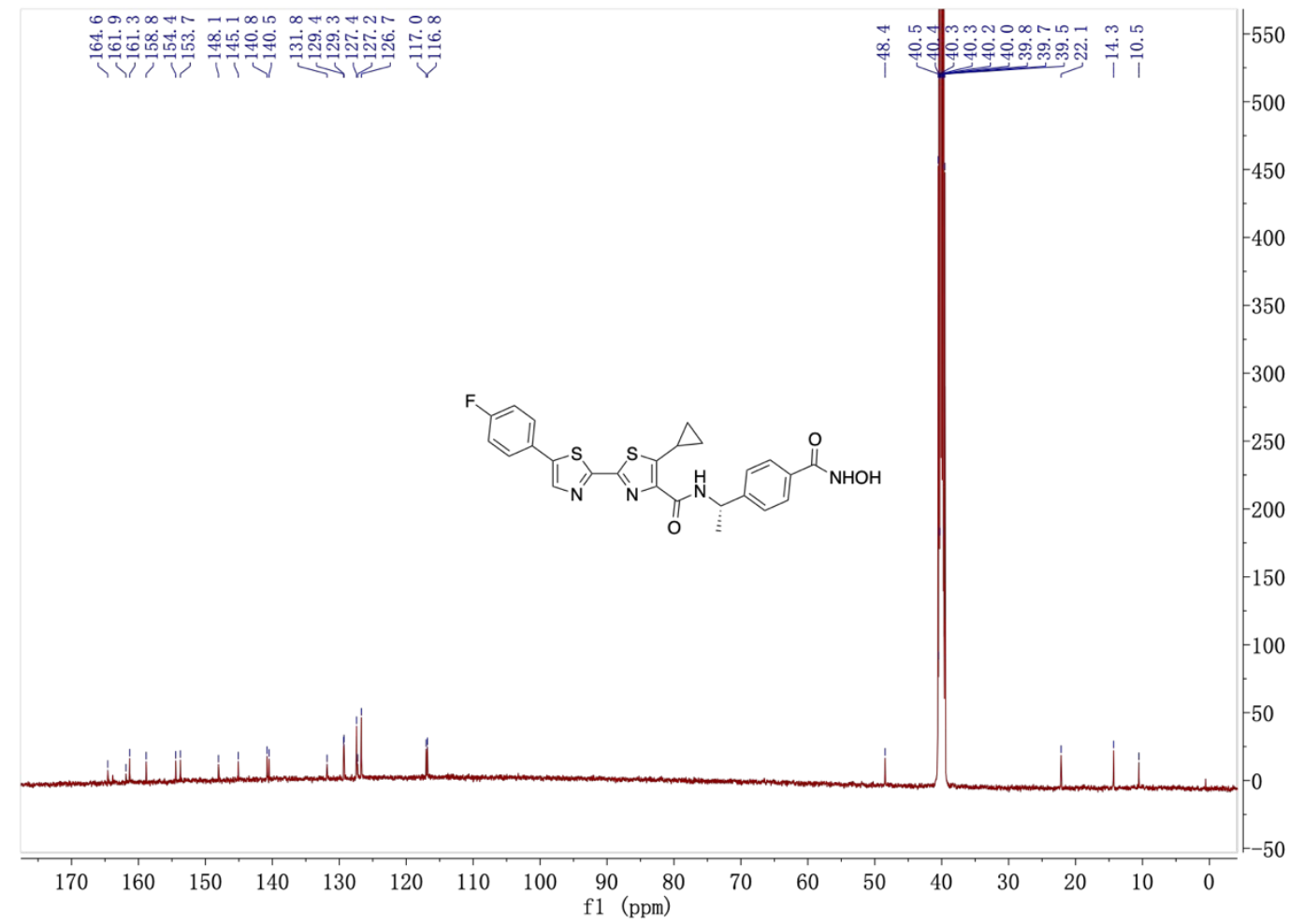


${ }^{1} \mathrm{H}$ NMR of compound H15

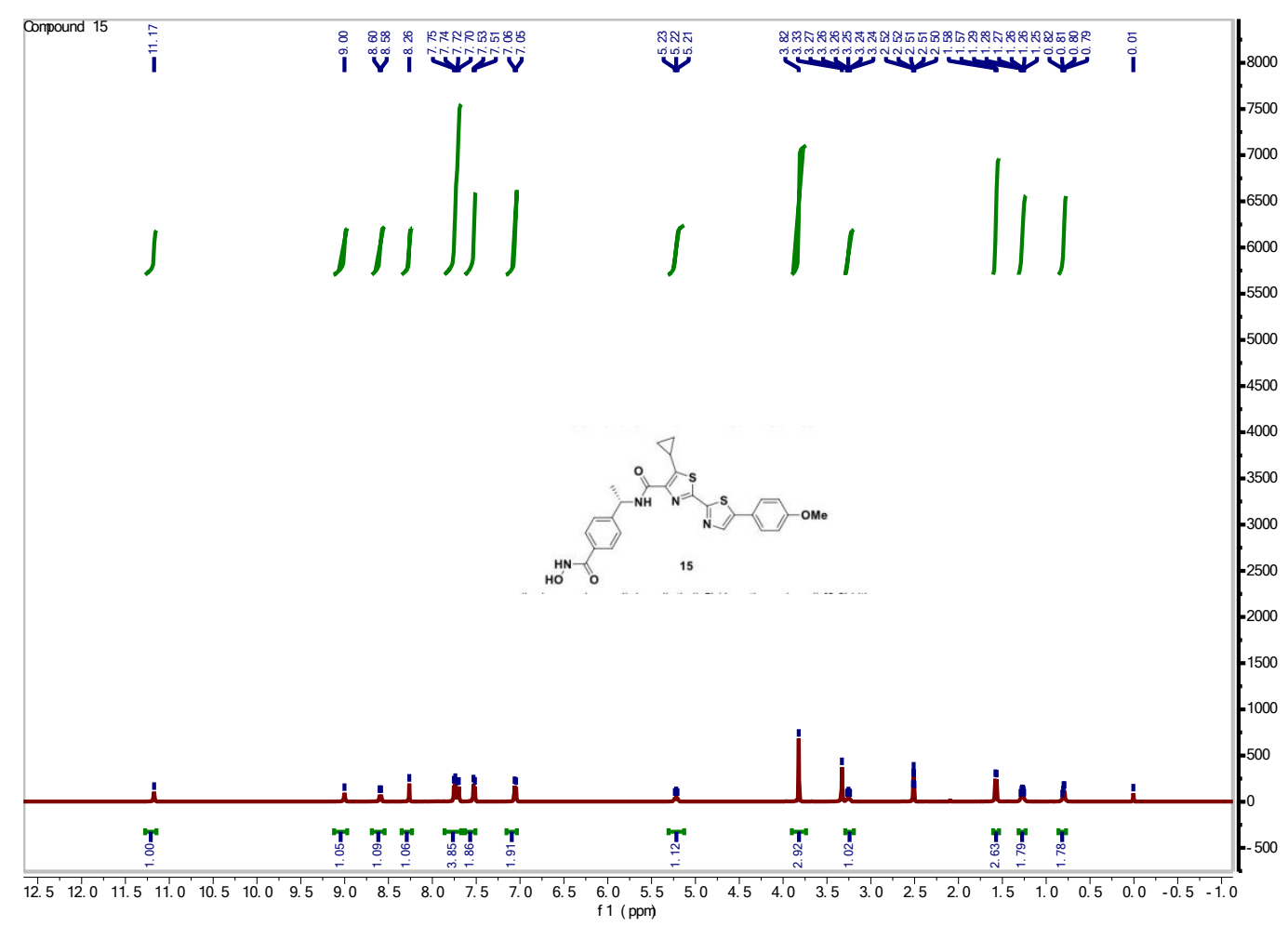

${ }^{13} \mathrm{C}$ NMR of compound H15

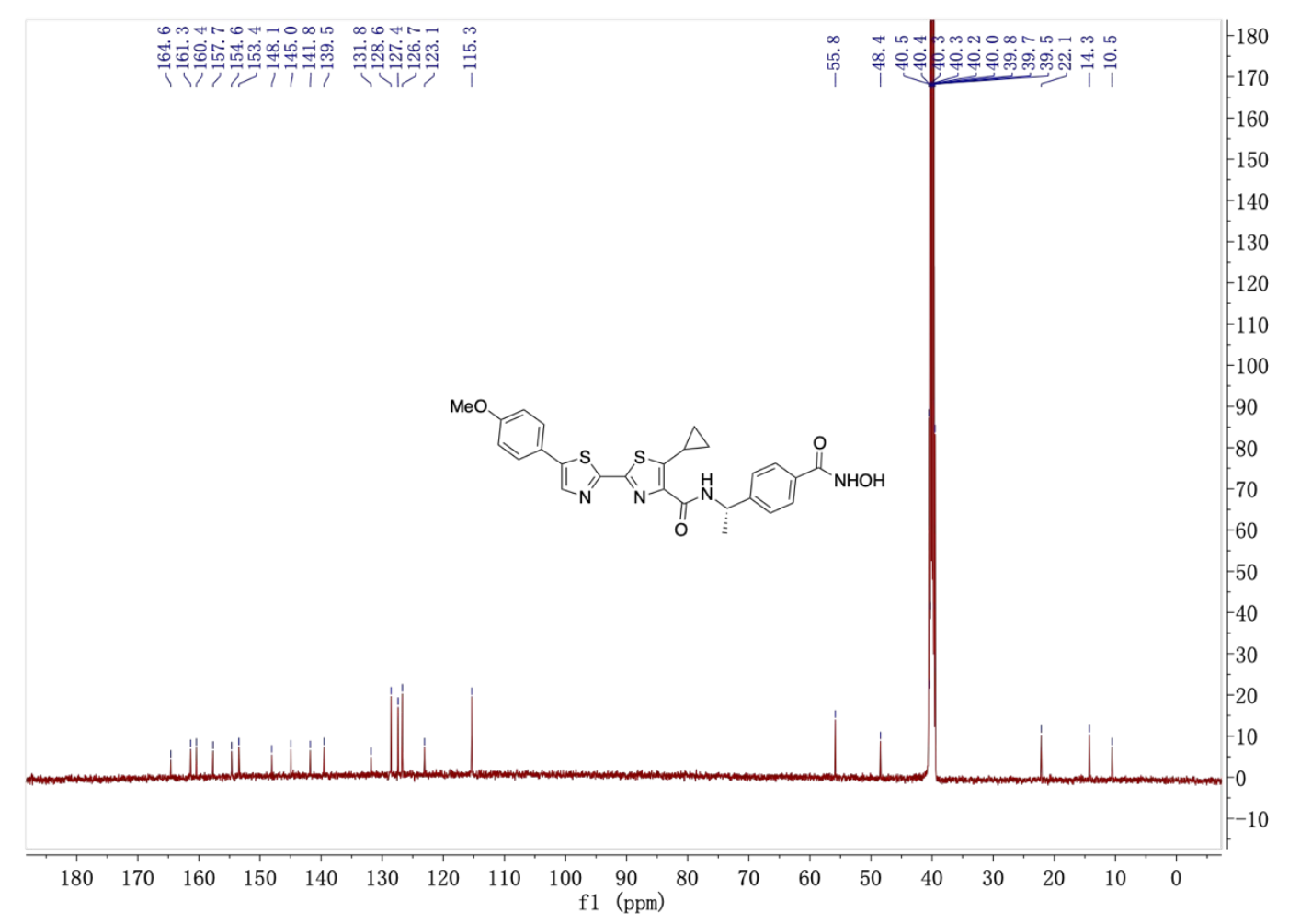




\section{The HPLC spectrums of compound H2-15}

The HPLC spectrum of compound $\mathrm{H} 2$

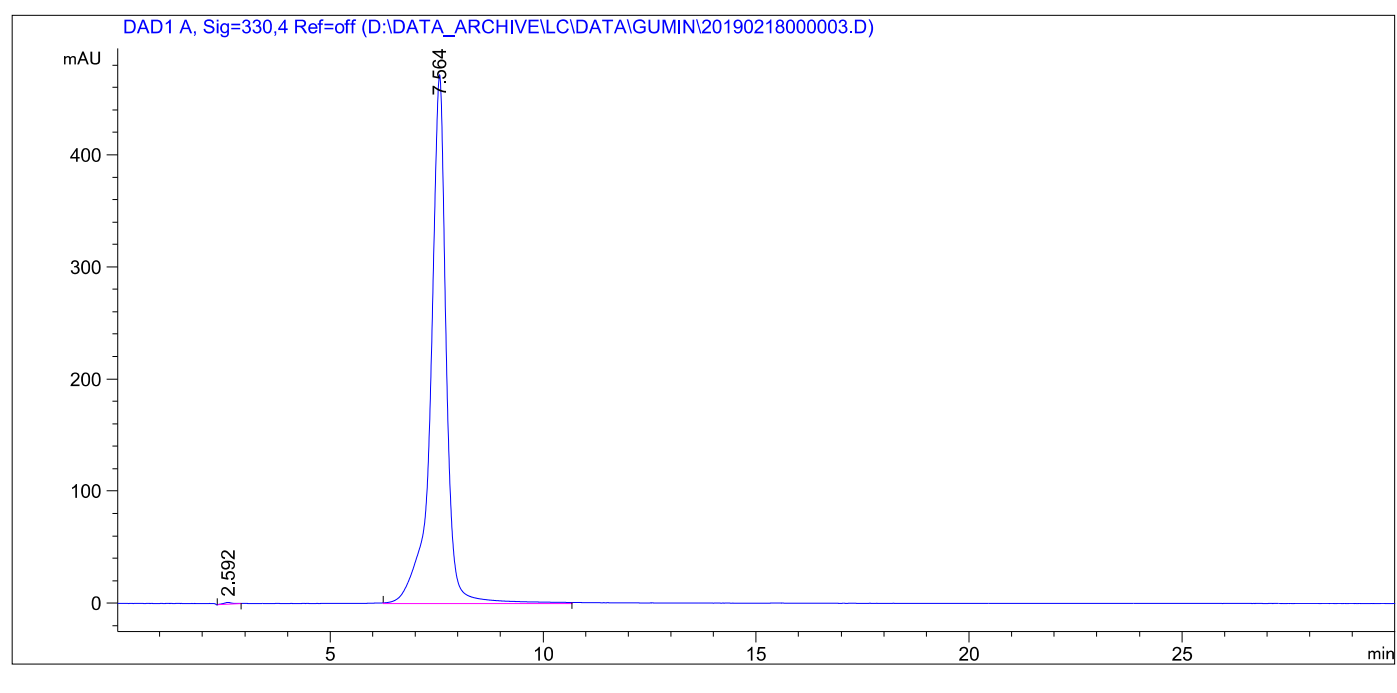

Area Percent Report

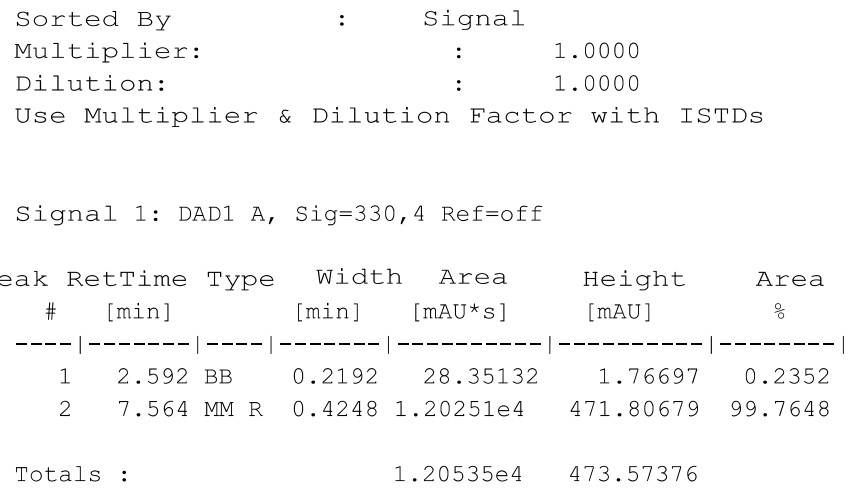

The HPLC spectrum of compound H3 


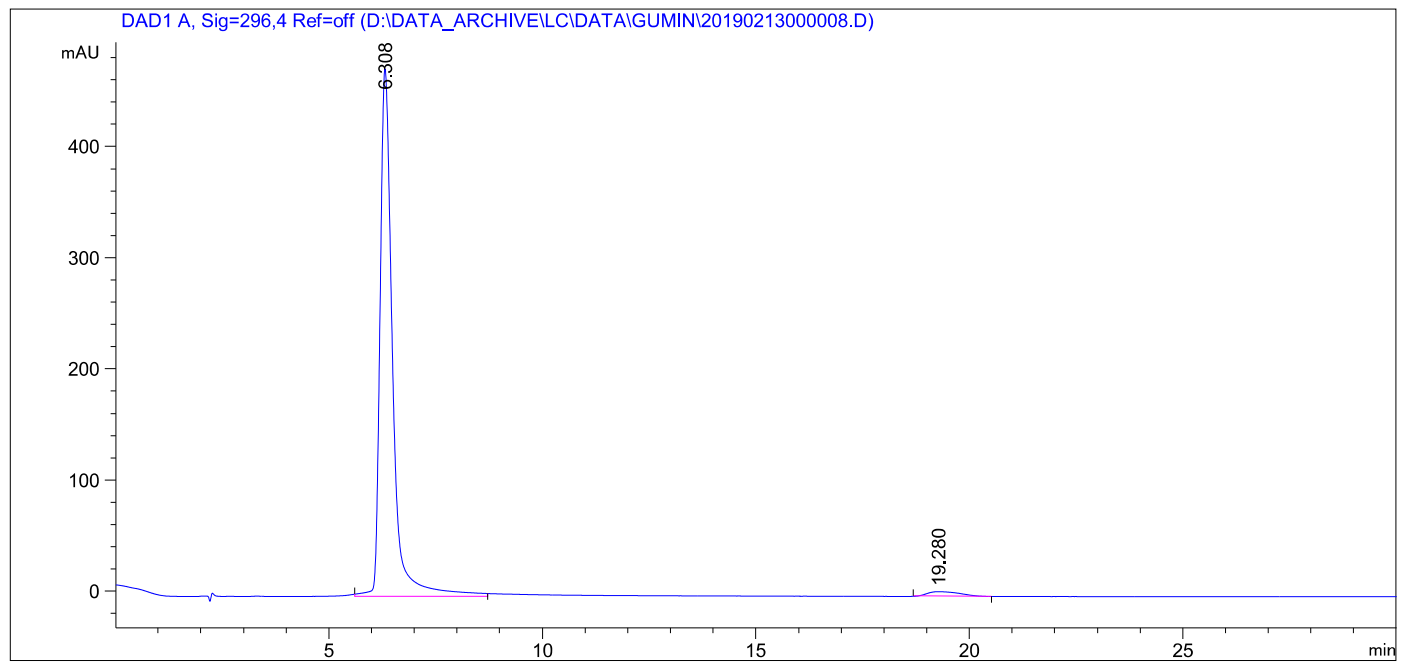

Area Percent Report

$\begin{array}{lccc}\text { Sorted By } & : & \text { Signal } \\ \text { Multiplier: } & : & 1.0000 \\ \text { Dilution: } & : & 1.0000 \\ \text { Use Multiplier \& Dilution } & \text { Factor with ISTDs }\end{array}$

Signal 1: DAD1 A, Sig=296,4 Ref=off

\begin{tabular}{|c|c|c|c|c|c|c|}
\hline $\begin{array}{r}\text { Peak } \\
\#\end{array}$ & $\begin{array}{c}\text { RetTime } \\
\quad[\min ]\end{array}$ & Type & $\begin{array}{l}\text { Width } \\
\text { [min] }\end{array}$ & $\begin{array}{c}\text { Area } \\
{\left[\mathrm{mAU}^{*} \mathrm{~s}\right]}\end{array}$ & $\begin{array}{l}\text { Height } \\
{[\mathrm{mAU}]}\end{array}$ & $\begin{array}{c}\text { Area } \\
\frac{\circ}{0}\end{array}$ \\
\hline \multirow{2}{*}{\multicolumn{7}{|c|}{ 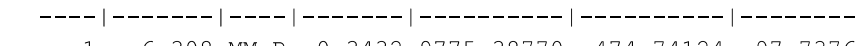 }} \\
\hline & & $\mathrm{MM} \mathrm{R}$ & 0.3432 & 9775.38770 & 474.74124 & 97.7376 \\
\hline & 19.280 & $\mathrm{BB}$ & 0.6341 & 226.27522 & 4.25738 & 2.2624 \\
\hline Tot & tals: & & & $1.00017 \mathrm{e} 4$ & 478.99862 & \\
\hline
\end{tabular}

The HPLC spectrum of compound H4 


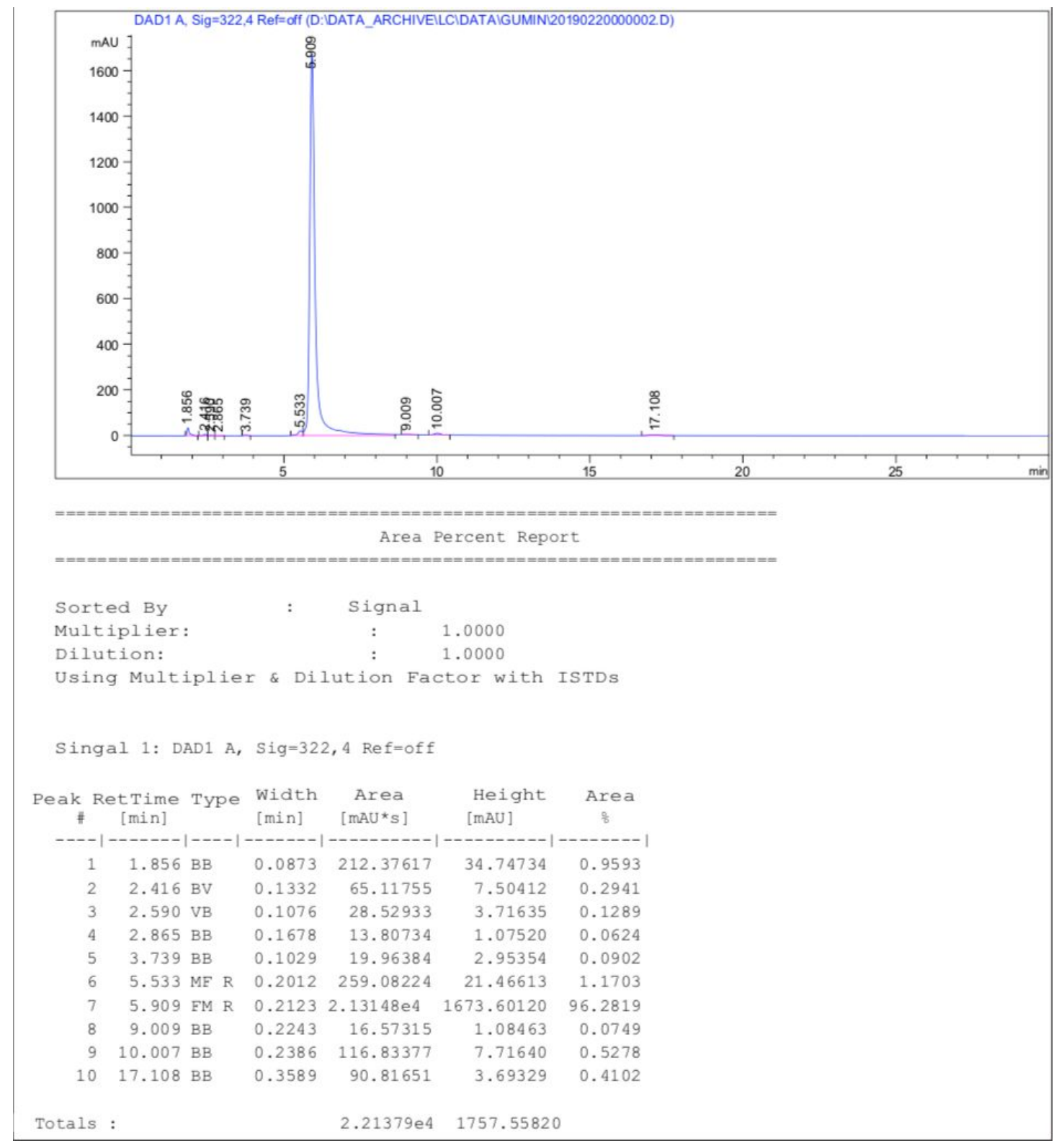

The HPLC spectrum of compound H5 


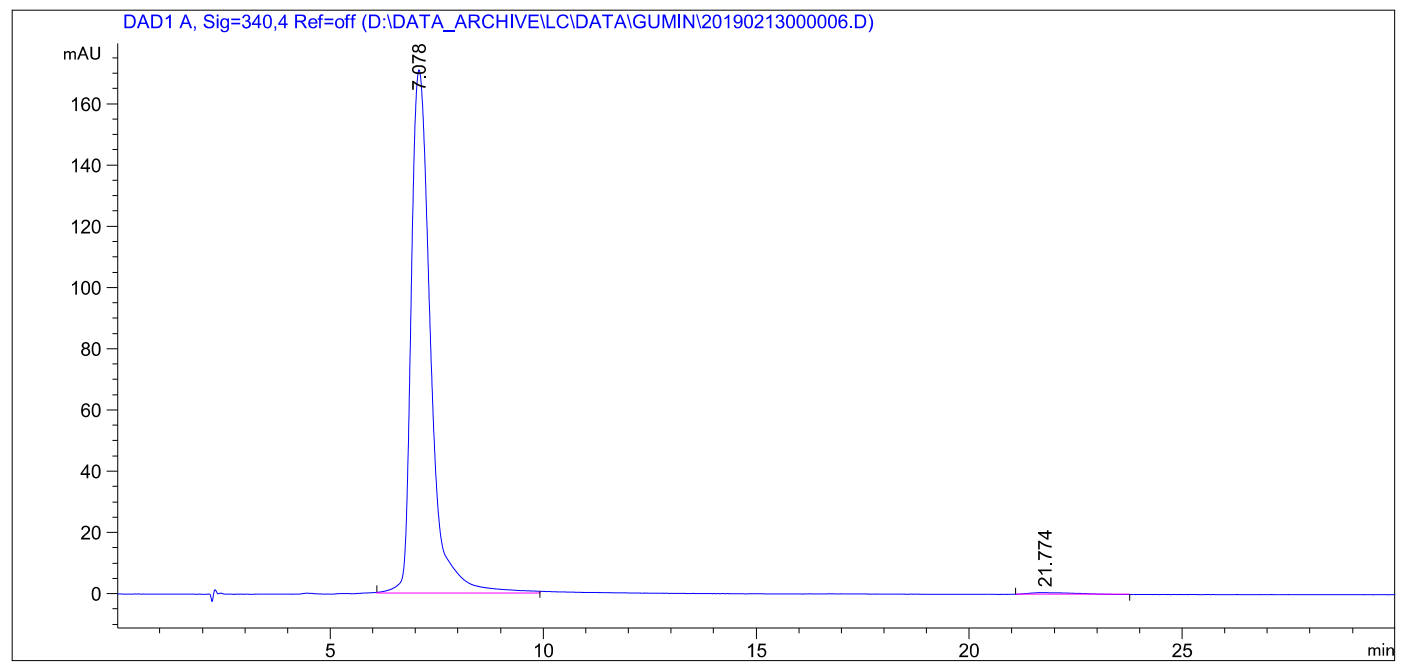

Area Percent Report

$\begin{array}{lccc}\text { Sorted By } & : & \text { Signal } & \\ \text { Multiplier: } & : & 1.0000 \\ \text { Dilution: } & : & 1.0000 \\ \text { Use Multiplier \& Dilution } & \text { Factor with ISTDs }\end{array}$

Signal 1: DAD1 A, Sig=340,4 Ref=off

\begin{tabular}{|c|c|c|c|c|c|c|}
\hline $\begin{array}{r}\text { Peak } \\
\text { \# }\end{array}$ & $\begin{array}{l}\text { RetTime } \\
\# \quad[\mathrm{~min}]\end{array}$ & Type & $\begin{array}{l}\text { Width } \\
{[\min ]}\end{array}$ & $\begin{array}{r}\text { Area } \\
{\left[\mathrm{mAU}^{*} \mathrm{~s}\right]}\end{array}$ & $\begin{array}{l}\text { Height } \\
\text { [mAU] }\end{array}$ & $\begin{array}{c}\text { Area } \\
\div\end{array}$ \\
\hline & & & & & & \\
\hline & 7.078 & MM R & 0.5323 & 5461.71533 & 171.00699 & 98.9470 \\
\hline & 774 & & 1.0472 & 58.12592 & $4956 e-1$ & 1.0530 \\
\hline
\end{tabular}

$\begin{array}{lll}\text { Totals : } & 5519.84126 \quad 171.68194\end{array}$

The HPLC spectrum of compound H6b 


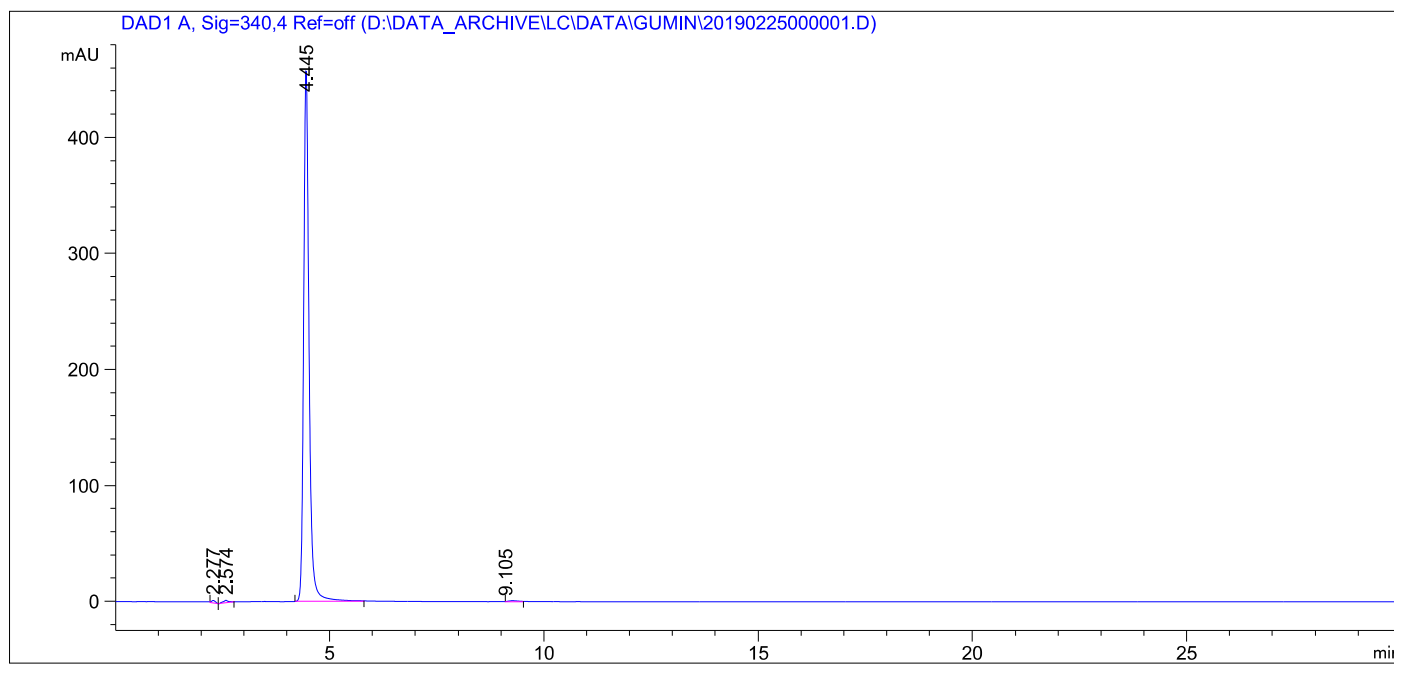

Area Percent Report

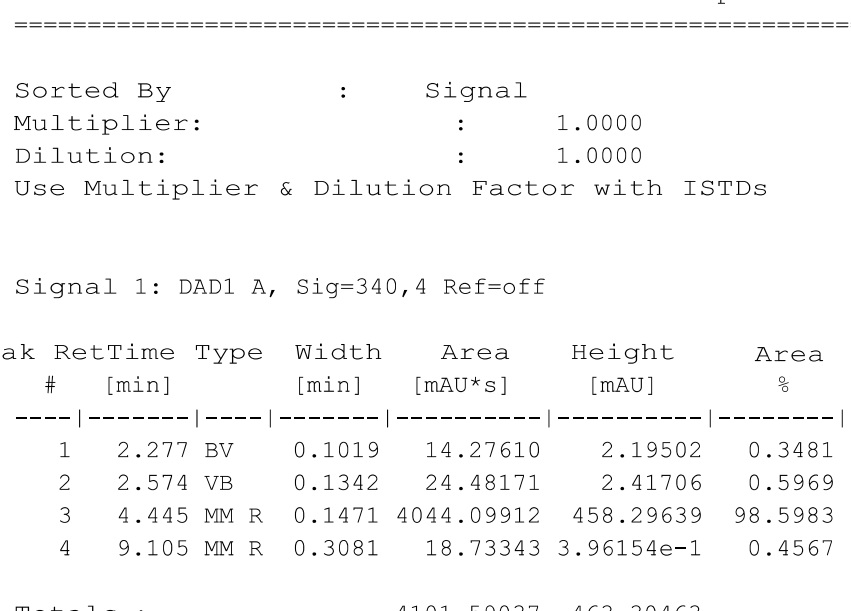

Totals : $\quad 4101.59037 \quad 463.30463$

The HPLC spectrum of compound H7 


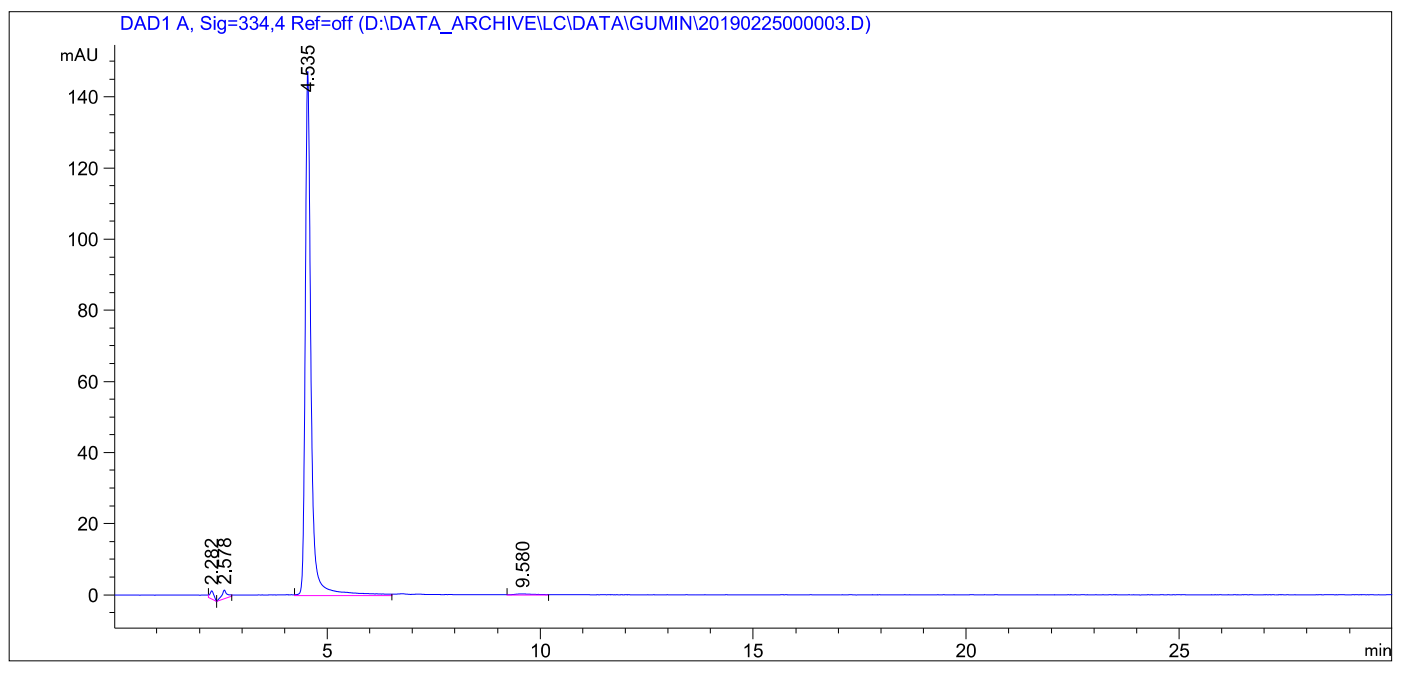

Area Percent Report

$\begin{array}{lcc}\text { Sorted By } & : & \text { Signal } \\ \text { Multiplier: } & : & 1.0000 \\ \text { Dilution: } & : & 1.0000 \\ \text { Use Multiplier \& Dilution Factor with ISTDs }\end{array}$

Signal 1: DAD1 A, Sig=334,4 Ref=off

\begin{tabular}{|c|c|c|c|c|c|c|c|}
\hline Peak & $\mathrm{Re}$ & $\begin{array}{l}=\text { Time } \\
\text { [min] }\end{array}$ & Type & $\begin{array}{l}\text { Width } \\
\text { [min] }\end{array}$ & $\begin{array}{c}\text { Area } \\
{\left[\mathrm{mAU}^{*} \mathrm{~s}\right]}\end{array}$ & $\begin{array}{l}\text { Height } \\
{[\mathrm{mAU}]}\end{array}$ & $\begin{array}{c}\text { Area } \\
\frac{\circ}{0}\end{array}$ \\
\hline \multicolumn{8}{|c|}{$----|-------|----|-------|----------|----------|--------$} \\
\hline & 1 & 2.282 & BV & 0.0941 & 14.84900 & 2.33776 & 1.0111 \\
\hline & 2 & 2.578 & VB & 0.1255 & 23.84694 & 2.54188 & 1.6237 \\
\hline & 3 & 4.535 & MM R & 0.1601 & 1417.15942 & 147.57425 & 96.4948 \\
\hline & 4 & 9.580 & MM R & 0.6189 & 12.78293 & $3.44249 e-1$ & 0.8704 \\
\hline
\end{tabular}

$\begin{array}{lll}\text { Totals : } & 1468.63829 & 152.79814\end{array}$

The HPLC spectrum of compound H8 


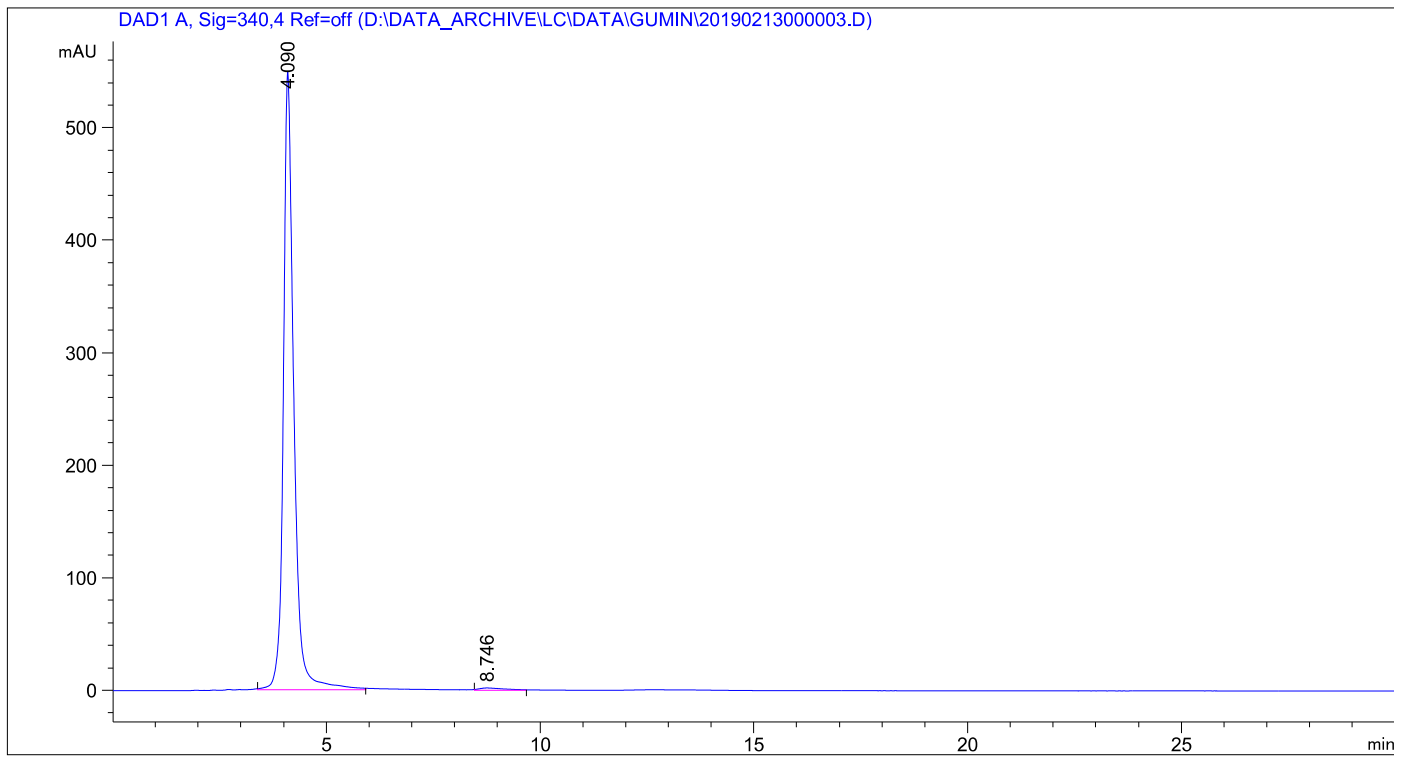

Area Percent Report

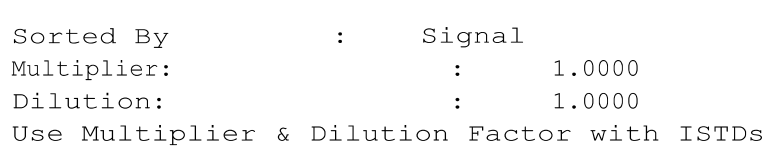

Signal 1: DAD1 A, Sig=340,4 Ref=off

\begin{tabular}{|c|c|c|c|c|c|c|}
\hline $\begin{array}{c}\text { Peak } \\
\#\end{array}$ & $\begin{array}{c}\text { RetTime } \\
\text { [min] }\end{array}$ & Type & $\begin{array}{l}\text { Width } \\
\text { [min] }\end{array}$ & $\begin{array}{r}\text { Area } \\
{\left[\mathrm{mAU}^{\star} \mathrm{s}\right]}\end{array}$ & $\begin{array}{l}\text { Height } \\
{[\mathrm{mAU}]}\end{array}$ & $\begin{array}{r}\text { Area } \\
\frac{\circ}{0}\end{array}$ \\
\hline---- & $-\mid-------$ & $|----|$ & ----- & ----------- & ---------- & $|--------|$ \\
\hline 1 & 4.090 & MM $\mathrm{R}$ & 0.2844 & 9378.21582 & 549.56299 & 98.6806 \\
\hline 2 & 8.746 & $\mathrm{MM} R$ & 0.8229 & 125.39435 & 2.53975 & 1.3194 \\
\hline Tot & cals & & & 9503.61017 & 552.10274 & \\
\hline
\end{tabular}

The HPLC spectrum of compound H9 


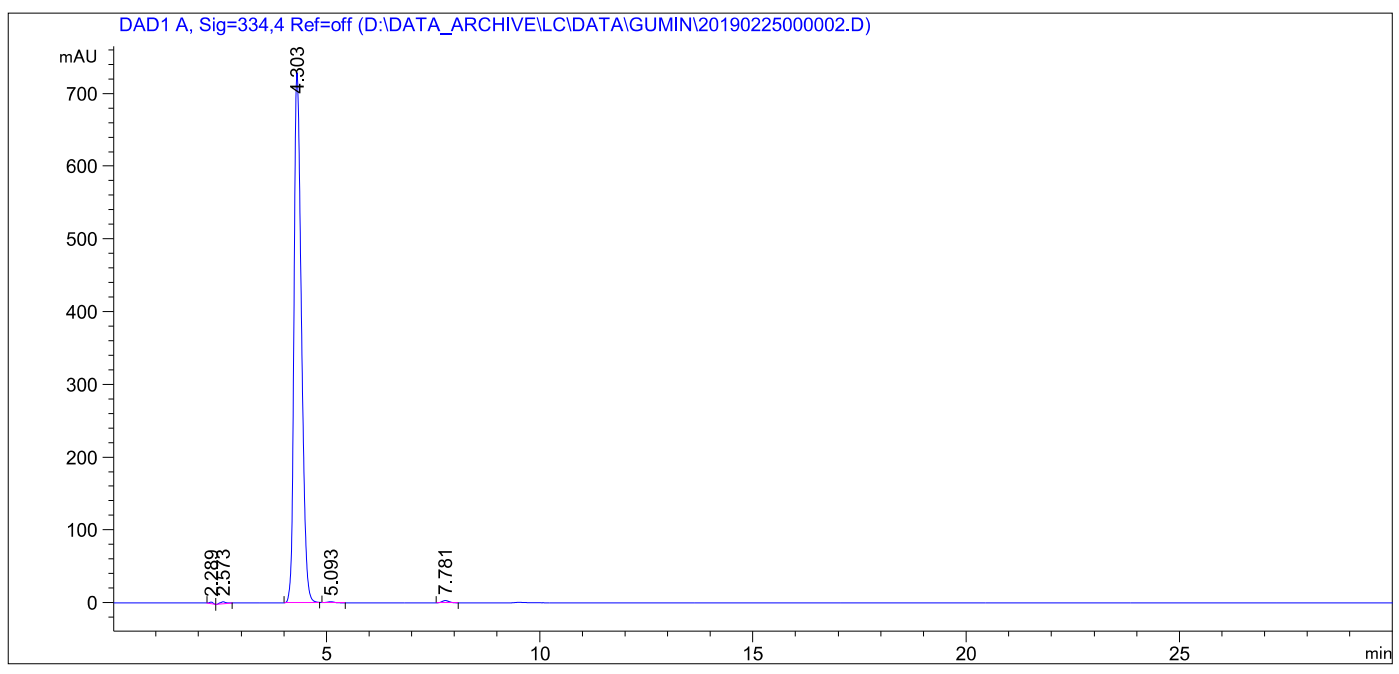

Area Percent Report

\begin{tabular}{|c|c|c|}
\hline Sorted by & : & Signal \\
\hline Multiplier: & & : \\
\hline Dilution: & & : \\
\hline
\end{tabular}

Use Multiplier \& Dilution Factor with ISTDS

Signal 1: DAD1 A, Sig=334,4 Ref=off

\begin{tabular}{|c|c|c|c|c|c|c|c|}
\hline $\begin{array}{r}\text { Peak } \\
\#\end{array}$ & & $\begin{array}{l}\text { tTime } \\
\text { [min] }\end{array}$ & Type & $\begin{array}{l}\text { Width } \\
\text { [min] }\end{array}$ & $\begin{array}{c}\text { Area } \\
{\left[\mathrm{mAU}^{*} \mathrm{~s}\right]}\end{array}$ & $\begin{array}{l}\text { Height } \\
{[\mathrm{mAU}]}\end{array}$ & $\begin{array}{c}\text { Area } \\
\div\end{array}$ \\
\hline \multicolumn{8}{|c|}{$----|-------|----|-------|----------|----------|--------\mid$} \\
\hline & 1 & 2.289 & BV & 0.1024 & 16.38903 & 2.50152 & 0.1839 \\
\hline & 2 & 2.573 & $\mathrm{VB}$ & 0.1427 & 33.64387 & 3.14793 & 0.3774 \\
\hline & 3 & 4.303 & $\mathrm{BB}$ & 0.1889 & 8806.05566 & 729.04413 & 98.7854 \\
\hline & 4 & 5.093 & $\mathrm{BB}$ & 0.1842 & 20.16231 & 1.56579 & 0.2262 \\
\hline & 5 & 7.781 & $\mathrm{BB}$ & 0.1809 & 38.07889 & 3.24415 & 0.4272 \\
\hline \multicolumn{3}{|c|}{ Totals : } & & & 8914.32977 & 739.50352 & \\
\hline
\end{tabular}

The HPLC spectrum of compound H10 


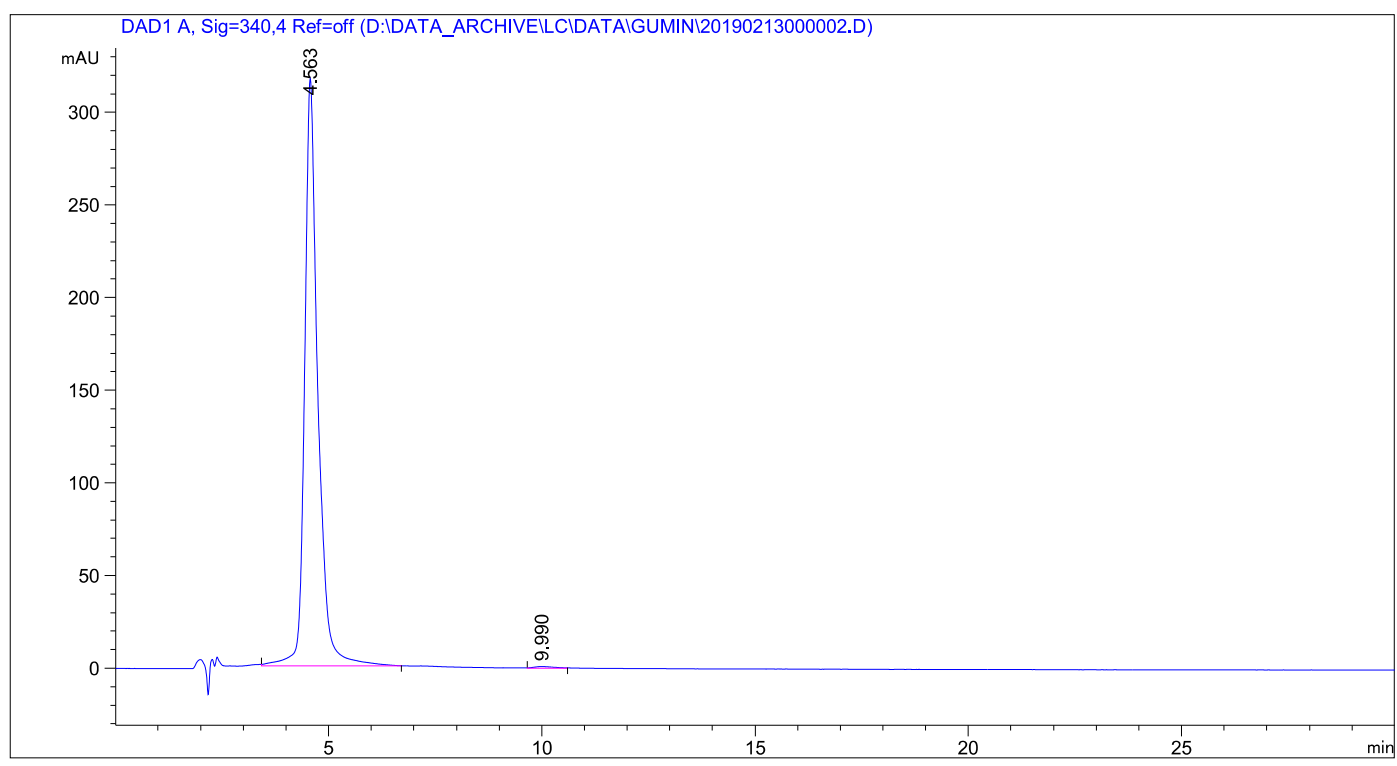

Area Percent Report

\begin{tabular}{|c|c|c|c|}
\hline Sorted By & $:$ & Signal & \\
\hline Multiplier: & & : & 1.0000 \\
\hline Dilution: & & : & 1.0000 \\
\hline
\end{tabular}

Use Multiplier \& Dilution Factor with ISTDS

Signal 1: DAD1 A, Sig=340,4 Ref=off

\begin{tabular}{|c|c|c|c|c|c|c|}
\hline $\begin{array}{r}\text { Peak } \\
\#\end{array}$ & $\begin{array}{c}\text { RetTime } \\
{[\mathrm{min}]}\end{array}$ & & $\begin{array}{r}\text { pewidth } \\
\text { [min] }\end{array}$ & $\begin{array}{l}\text { Area } \\
{\left[\mathrm{mAU}{ }^{*} \mathrm{~s}\right]}\end{array}$ & $\begin{array}{l}\text { Height } \\
{[\mathrm{mAU}]}\end{array}$ & $\begin{array}{r}\text { Area } \\
\frac{\circ}{0}\end{array}$ \\
\hline \multicolumn{7}{|c|}{$---|-------|---------|---------|--$} \\
\hline & 4.563 & MM & 0.3539 & 6911.81445 & 317.10425 & 99.5916 \\
\hline & 9.990 & MM & 0.5494 & 28.34672 & $8.59954 e^{-1}$ & 0.4084 \\
\hline Tot & tals & & & 6940.16117 & 317.96420 & \\
\hline
\end{tabular}

The HPLC spectrum of compound H11 


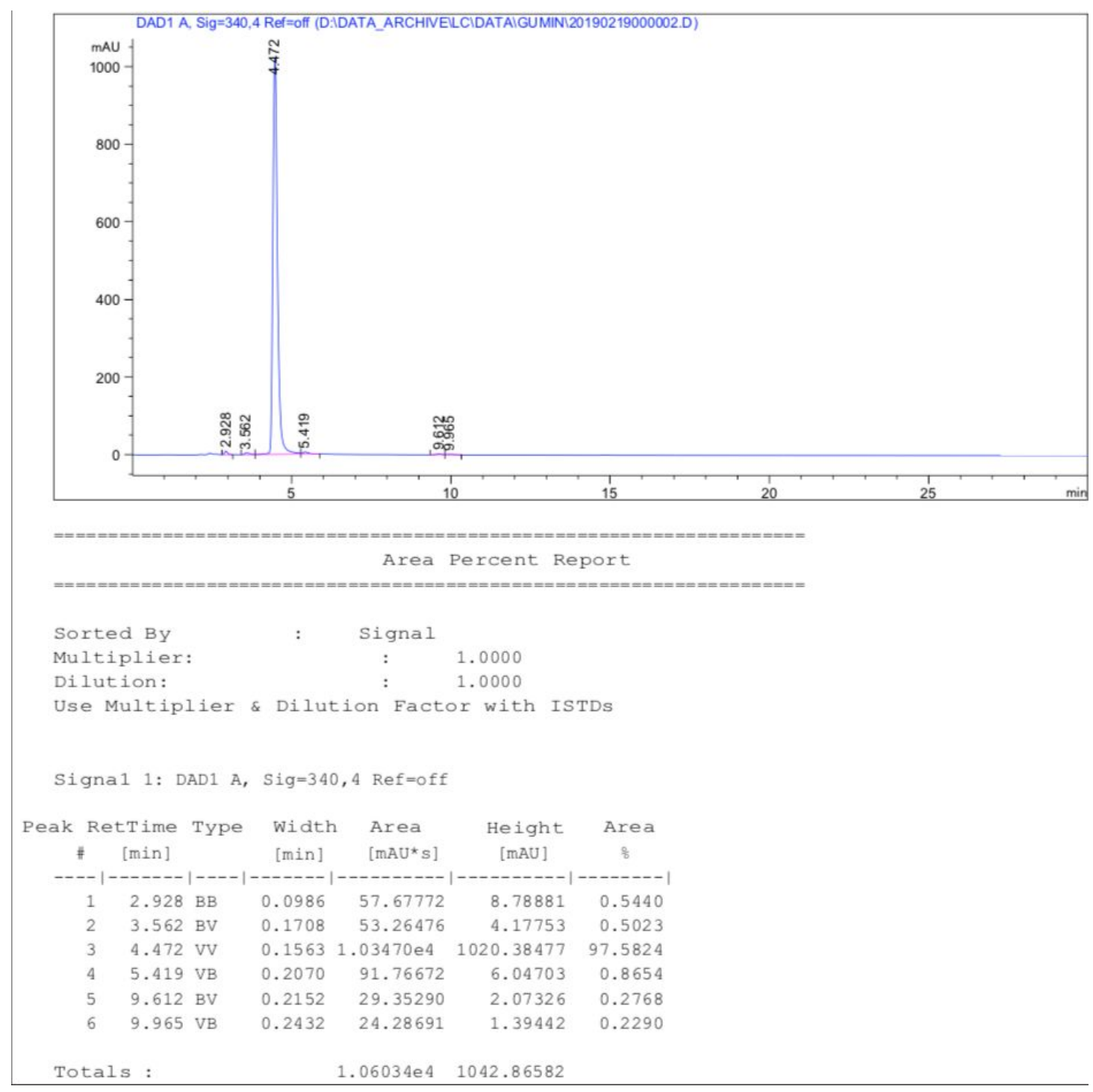

The HPLC spectrum of compound H12 


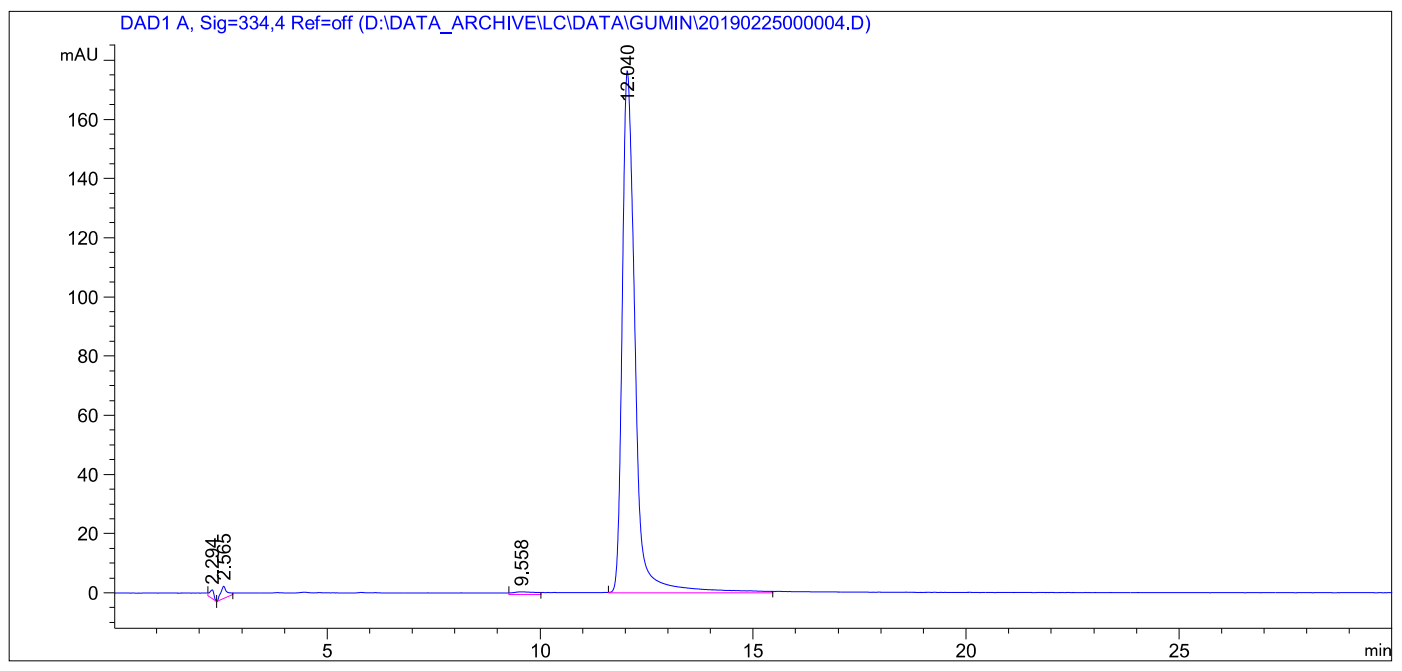

Area Percent Report

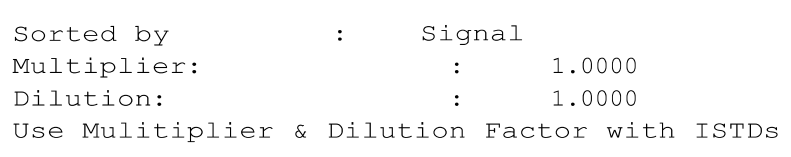

Signal 1: DAD1 A, Sig=334,4 Ref=off

\begin{tabular}{|c|c|c|c|c|c|c|}
\hline $\begin{array}{r}\text { Peak } \\
\#\end{array}$ & $\begin{array}{c}\text { RetTime } \\
\text { [min] }\end{array}$ & Type & $\begin{array}{l}\text { Width } \\
\text { [min] }\end{array}$ & $\begin{array}{c}\text { Area } \\
{\left[\mathrm{mAU}^{*} \mathrm{~s}\right]}\end{array}$ & $\begin{array}{l}\text { Height } \\
\text { [mAU] }\end{array}$ & $\begin{array}{c}\text { Area } \\
\frac{\circ}{0}\end{array}$ \\
\hline \multicolumn{7}{|c|}{$----|-------|----|-------|----------|----------|--------\mid$} \\
\hline & 12.294 & BV & 0.1045 & 19.76233 & 2.93568 & 0.5113 \\
\hline 2an & 2.565 & $\mathrm{VB}$ & 0.1453 & 45.45641 & 4.23347 & 1.1762 \\
\hline sis & 9.558 & MM R & 0.6399 & 36.45898 & $9.49529 e-1$ & 0.9434 \\
\hline sen & 12.040 & MM R & 0.3554 & 3763.12988 & 176.48820 & 97.3691 \\
\hline Tot & zals: & & & 3864.80760 & 184.60688 & \\
\hline
\end{tabular}

The HPLC spectrum of compound H13 


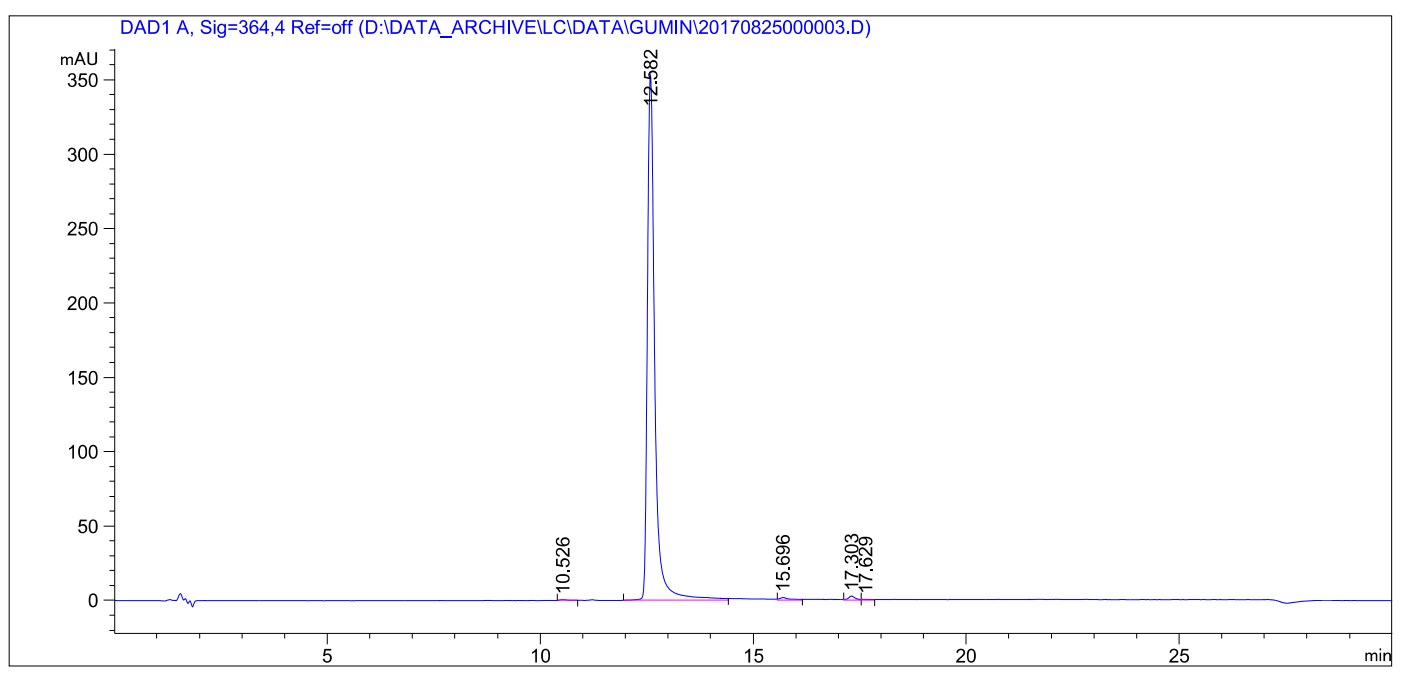

Area Percent Report

$\begin{array}{lccc}\text { Sorted By } & : & \text { Signal } & \\ \text { Multiplier: } & & : & 1.0000 \\ \text { Dilution: } & & : & 1.0000\end{array}$

Use Multiplier \& Dilution Factor with ISTDs

Signal 1: DAD1 A, Sig=364,4 Ref=off

\begin{tabular}{|c|c|c|c|c|c|c|}
\hline $\begin{array}{r}\text { Peak } \\
\#\end{array}$ & $\begin{array}{c}\text { RetTime } \\
\text { [min] }\end{array}$ & Type & $\begin{array}{l}\text { Width } \\
\text { [min] }\end{array}$ & $\begin{array}{c}\text { Area } \\
{\left[\mathrm{mAU}{ }^{\star} \mathrm{s}\right]}\end{array}$ & $\begin{array}{l}\text { Height } \\
\text { [mAU] }\end{array}$ & $\begin{array}{c}\text { Area } \\
\frac{\circ}{0}\end{array}$ \\
\hline \multicolumn{7}{|c|}{$----|-------|----|-------|----------|----------|--------$} \\
\hline 1 & 10.526 & $\mathrm{HH}$ & 0.2180 & 9.37288 & $6.14443 e-1$ & 0.2114 \\
\hline 2 & 12.582 & $\mathrm{HH}$ & 0.1872 & 4329.95264 & 352.78400 & 97.6466 \\
\hline 3 & 15.696 & $\mathrm{HH}$ & 0.2693 & 41.78839 & 2.05447 & 0.9424 \\
\hline 4 & 17.303 & $\mathrm{HH}$ & 0.1868 & 38.70927 & 2.99495 & 0.8729 \\
\hline 5 & 17.629 & $\mathrm{HH}$ & 0.2398 & 14.48732 & $8.45836 e-1$ & 0.3267 \\
\hline
\end{tabular}

总量： $4434.31049 \quad 359.29370$

The HPLC spectrum of compound H14 


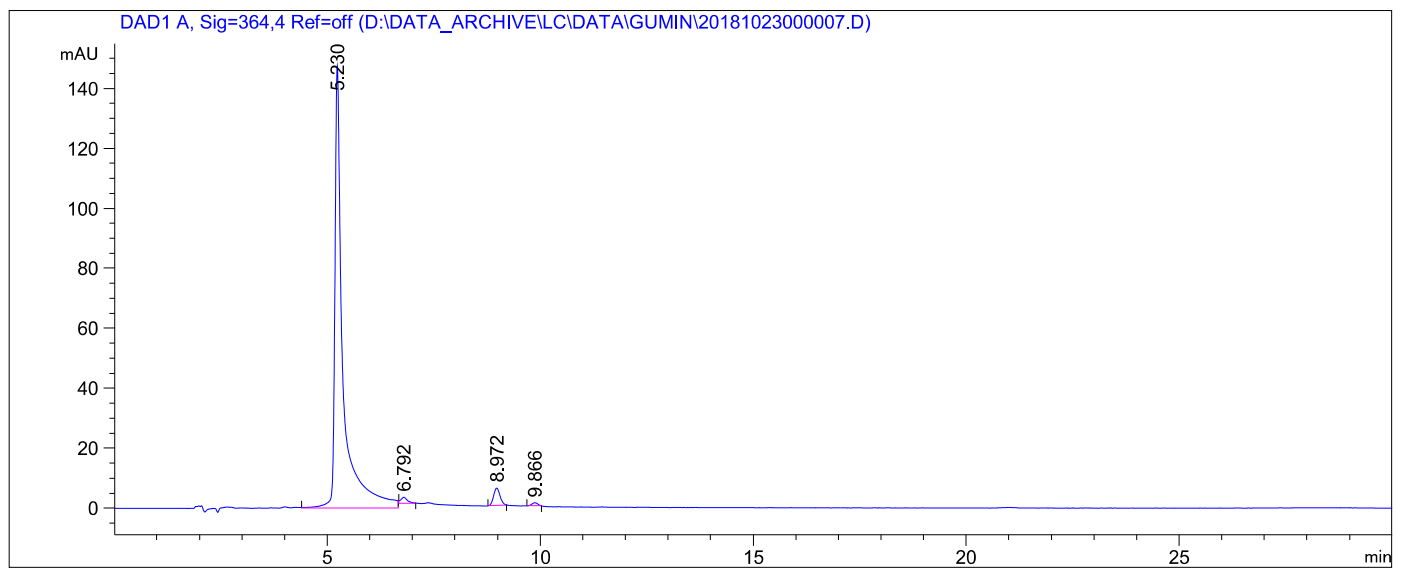

Area Percent Report

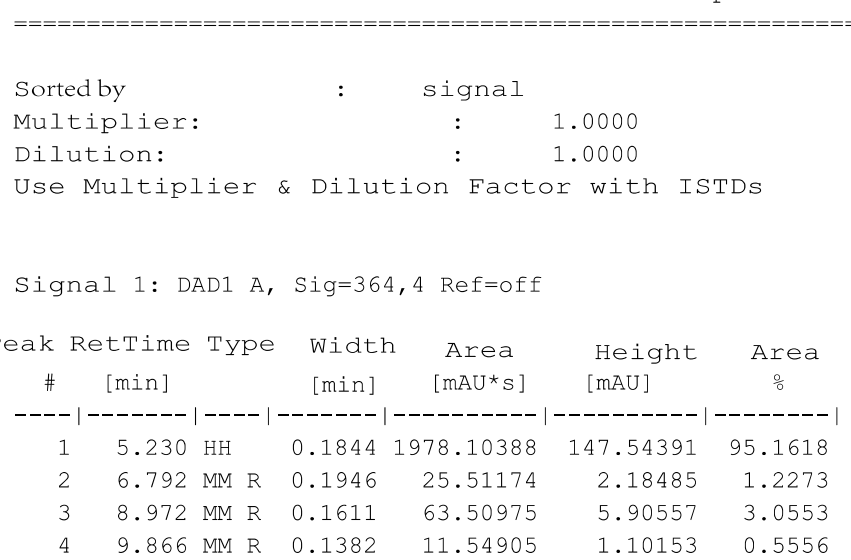

Totals : $\quad 2078.67442 \quad 156.73587$

The HPLC spectrum of compound H15 


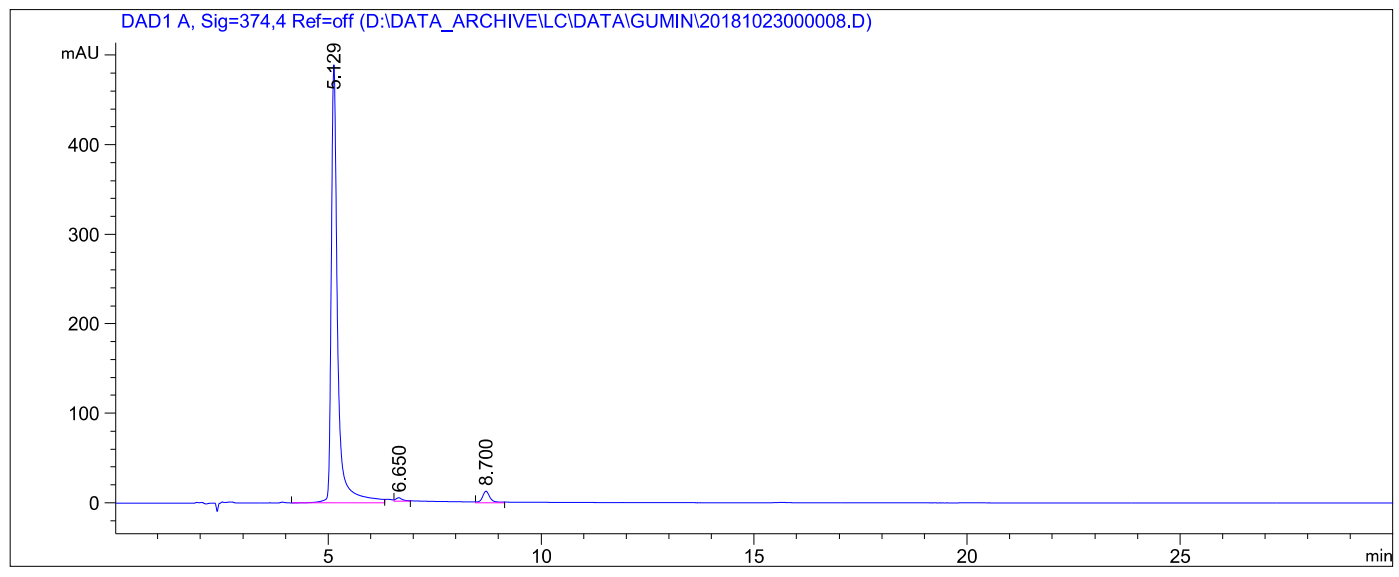

Area Percent Report

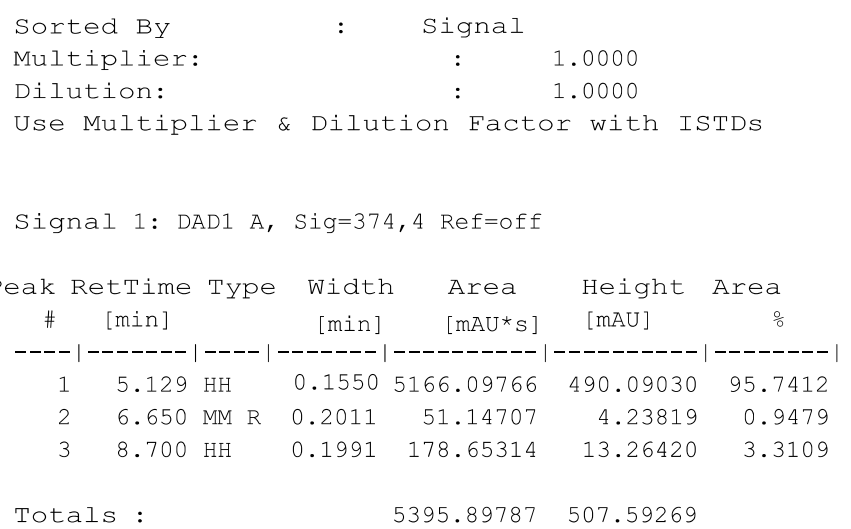

\section{Enzymatic assay with recombinant human HDACs}

Eleven rhHDACs (recombinant humanHDACs) were expressed in insect High5 cells using a baculoviral expression system, with the exception of HDAC5/7/9 which was purchased from BPS Biosciences, and all His $_{6}$-tagged and GST-fusion proteins were purified using Ni-NTA (QIAGEN). The deacetylase activity of HDAC1,2,3, 8,10 and 11 were assayed with a HDAC substrate (Ac-Lys-Tyr-Lys(e-acetyl)-AMC), HDAC4,5,7,9 were assay with a HDAC II a substrate(Ac-Leu-Gly-Lys(Tfa)-AMC), and HDAC6 was assayed with another HDAC substrate(Boc-Lys(E-acetyl)-AMC). The total HDAC assay volume was $25 \mu 1$ and all the assay components were diluted in Hepes buffer (25 mM Hepes, $137 \mathrm{mM} \mathrm{NaCl}, 2.7 \mathrm{mM} \mathrm{KCl}$ and $4.9 \mathrm{mM} \mathrm{MgCl}_{2}, \mathrm{pH}$ 8.0). The 
reaction was carried out in black 384-well plates (OptiPlate ${ }^{\mathrm{TM}}-384 \mathrm{~F}$, PerkinElmer). In brief, the HDAC assay mixture contained HDAC substrate $(10 \mu \mathrm{M}$ for HDAC1,3,4,5,7,9,10, $5 \mu \mathrm{M}$ for HDAC8, $20 \mu \mathrm{M}$ for HDAC2,11, $50 \mu \mathrm{M}$ for HDAC6, $5 \mu \mathrm{l})$, rhHDAC isoforms (1-50 nM) and inhibitor (1 $\mu \mathrm{l})$ with LBH589 as positive control. And all assays were incubated for $24 \mathrm{~h}$ at room temperature. The reaction was quenched with the addition of $25 \mu 1$ Trypsin (diluted to final concentration $0.3125 \%$ ). The plates were incubated for $30 \mathrm{~min}$ at room temperature to allow the fluorescence signal to develop. The fluorescence generated was monitored at wavelengths $355 \mathrm{~nm}$ (excitation) and $460 \mathrm{~nm}$ (emission) using Envision (PerkinElmer). The dose response of inhibition test was carried out in triplicate. And the $\mathrm{IC}_{50}$ data was calculated using the software GraphPad Prism 5, and chosen the equation "sigmoidal dose-response (variable slope)" for curve fitting.

Recombinant human SIRT1 fused at the N-terminus to GST and expressed in E. coli. Recombinant human SIRT2 fused at the N-terminus to GST sequence and expressed in E. coli. Recombinant human SIRT3 fused at the N-terminus to a His•Tag and expressed in E. coli. The deacetylase activity of rhSIRTs (recombinant human SIRTs) 1, 2, and 3 was assayed with a substrate (Ac-Arg-His-Lys-Lys(Ac)-AMC).The total SIRT assay volume was $25 \mu \mathrm{l}$ and all the assay components were diluted in TrisHCl buffer (62.5 $\mathrm{mM}$ TrisHCl, $62.5 \mathrm{mM} \mathrm{NaCl}, 2.5 \mathrm{mM} \mathrm{MgCl}_{2}, 0.1 \% \mathrm{BSA}$ and $\%$ Glycerol, $\mathrm{pH}$ 8.4). The reaction was carried out in black 384-well plates (OptiPlateTM-384F, PerkinElmer). In brief, the SIRT assay mixture contained SIRT substrate $(100 \mu \mathrm{M})$, rhSIRTs isoforms $(50-100 \mathrm{nM})$ and compound sample $(1 \mu \mathrm{l})$. Positive controls contained all the above components and the inhibitor. The SIRT1 assay components were incubated at room temperature for $1 \mathrm{~h}$, and SIRT2,3 were incubated for $2 \mathrm{~h}$. The reaction was quenched with the addition of $5 \mu 1$ Trypsin (diluted to final concentration $0.3125 \%$ ). The plates were incubated for $2 \mathrm{~h}$ at room temperature to allow the fluorescence signal to develop. The fluorescence generated was monitored at wavelengths $355 \mathrm{~nm}$ (excitation) and 460nm(emission) using Envision (PerkinElmer). 


\section{Pharmacokinetic and distribution study.}

\subsection{Intravenous administration}

\section{Materials and Methods}

\section{Materials}

\section{Animals}

18 healthy ICR mice, half male and half female, weighing 18-20 g, fasted for $12 \mathrm{~h}$ before the test, free to drink water. Eat regularly 2 hours after administration.

\section{Chemicals}

The compound 13 was formulated as 5\% DMSO + 95\% 40\% PEG 400. Intravenous administration of $5 \mathrm{mg} / \mathrm{kg}$ in ICR mice.

\section{Methods}

At $20 \mathrm{~min}, 1 \mathrm{~h}, 6 \mathrm{~h}$ and $24 \mathrm{~h}$ after intravenous administration, the abdominal aorta was sacrificed by bloodletting, and 4 mice at each time point, half male and half female. 0.5 $\mathrm{ml}$ of whole blood was collected from each animal, placed in heparinized tubes, centrifuged at 11,000 rpm for $5 \mathrm{~min}$, and plasma was separated and stored frozen in a refrigerator at $-20{ }^{\circ} \mathrm{C}$. After the animals were sacrificed, the brain, liver, lung, kidney, stomach, small intestine, colon, ovary, uterus and testicles were dissected, and the residual blood was washed with ice physiological saline. After blotting, the label was sealed and stored in a refrigerator at $-20^{\circ} \mathrm{C}$. Take another 2 mice ( 1 male and 1 female) to take blank tissue. The concentration of each compound in plasma and tissue was determined by liquid chromatography tandem mass spectrometry.

\subsection{Oral administration}

\section{Materials and Methods}

\section{Materials}

\section{Animals}

14 healthy ICR mice, half male and half female, weighing 18-20 g, fasted for $12 \mathrm{~h}$ before the test, free to drink water. Eat regularly 2 hours after administration.

\section{Chemicals}


The compound 13 was formulated as $2 \%$ DMSO $+1 \%$ Cremophor EL $+97 \%$ $0.5 \% \mathrm{CMC}-\mathrm{Na}$. Oral administration of $50 \mathrm{mg} / \mathrm{kg}$ in ICR mice.

\section{Methods}

At $1 \mathrm{~h}, 6 \mathrm{~h}$ and $24 \mathrm{~h}$ after oral administration, the abdominal aorta was sacrificed by bloodletting, and 4 mice at each time point. $0.5 \mathrm{ml}$ of whole blood was collected from each animal, placed in heparinized tubes, centrifuged at 11,000 rpm for $5 \mathrm{~min}$, and plasma was separated and stored frozen in a refrigerator at $-20{ }^{\circ} \mathrm{C}$. After the animals were sacrificed, the brain, liver, lung, kidney, stomach, small intestine, colon, ovary, uterus and testicles were dissected, and the residual blood was washed with ice physiological saline. After blotting, the label was sealed and stored in a refrigerator at $-20{ }^{\circ} \mathrm{C}$. Take another 2 mice ( 1 male and 1 female) to take blank tissue. The concentration of each compound in plasma and tissue was determined by liquid chromatography tandem mass spectrometry.

\section{Colitis-associated colorectal cancer model}

\section{Materials and Methods}

\section{Animals}

C57BL/6 mice, 6-8 weeks old, were purchased from the BEIJING HFK BIOSCIENCE Co., LTD (Beijing, China). They were housed and maintained under specific pathogen-free conditions with a $12 \mathrm{~h}$ light/dark cycle at $25 \pm 1{ }^{\circ} \mathrm{C}$, and received food and water ad libitum. All experiments were carried out according to the institutional ethical guidelines on animal care and were approved by the Institute of Animal Care and Use Committee at the Shanghai Institute of Materia Medica (No. 2017-04-DJ-26).

\section{Chemicals}

Azoxymethane (AOM, A5486) were purchased from Sigma-Aldrich. Dextran sulfate sodium (DSS, 36-50 Kd, 0216011050) was purchased from MP Biomeicals.

\section{Induction and treatment of colitis-associated cancer}

To induce colitis-associated cancer (CAC), mice were injected intraperitoneally (i.p.) 
with a single dose $(7.5 \mathrm{mg} / \mathrm{kg})$ of AOM followed by 3 cycles of $2.5 \%$ DSS given in the drinking water for $5 \mathrm{~d}$ as reference (Autophagy 10:6, 972-985). Treatment groups received LBH589 or GCJ-490A by oral gavage at the indicated dose during the interval between DSS cycles. Mice were sacrificed on d156 after CAC induction.

\section{Computational modeling/docking studies of H6a and H6b}

We performed docking studies using the Schrodinger Suite. Compound H6a with a (S)methyl benzyl linker shows superior HDAC inhibition compared to Compound H6b with a R-enantiomer linker. These compounds were docked against eukaryotic, zincdependent $h$ HDAC6 (PDB: 5EDU). The receptor and ligand were prepared using the Protein Preparation Wizard and LigPrep module of the Schrodinger Suite, respectively. The docking analysis was carried out using the Ligand Docking module of Schrodinger's Glide. As showed in the following figure, the chiral methyl group determines the orientation of the compound in the pocket, the S-enantiomer preferentially interacts with residues H500, F620, F680 and H651. Thus, make the hydroxamic acid coordinates to zinc ions in the pocket of hHDAC6, While Renantiomer H6b participates in three hydrogen bonds (Y782, G619 and S568), which stiffens the benzyl group, thereby causing the hydroxamic acid to be incapable of coordinating with zinc ion. Therefore, it is reasonable to take the S-enantiomer H6a as a new starting point for further exploration. 

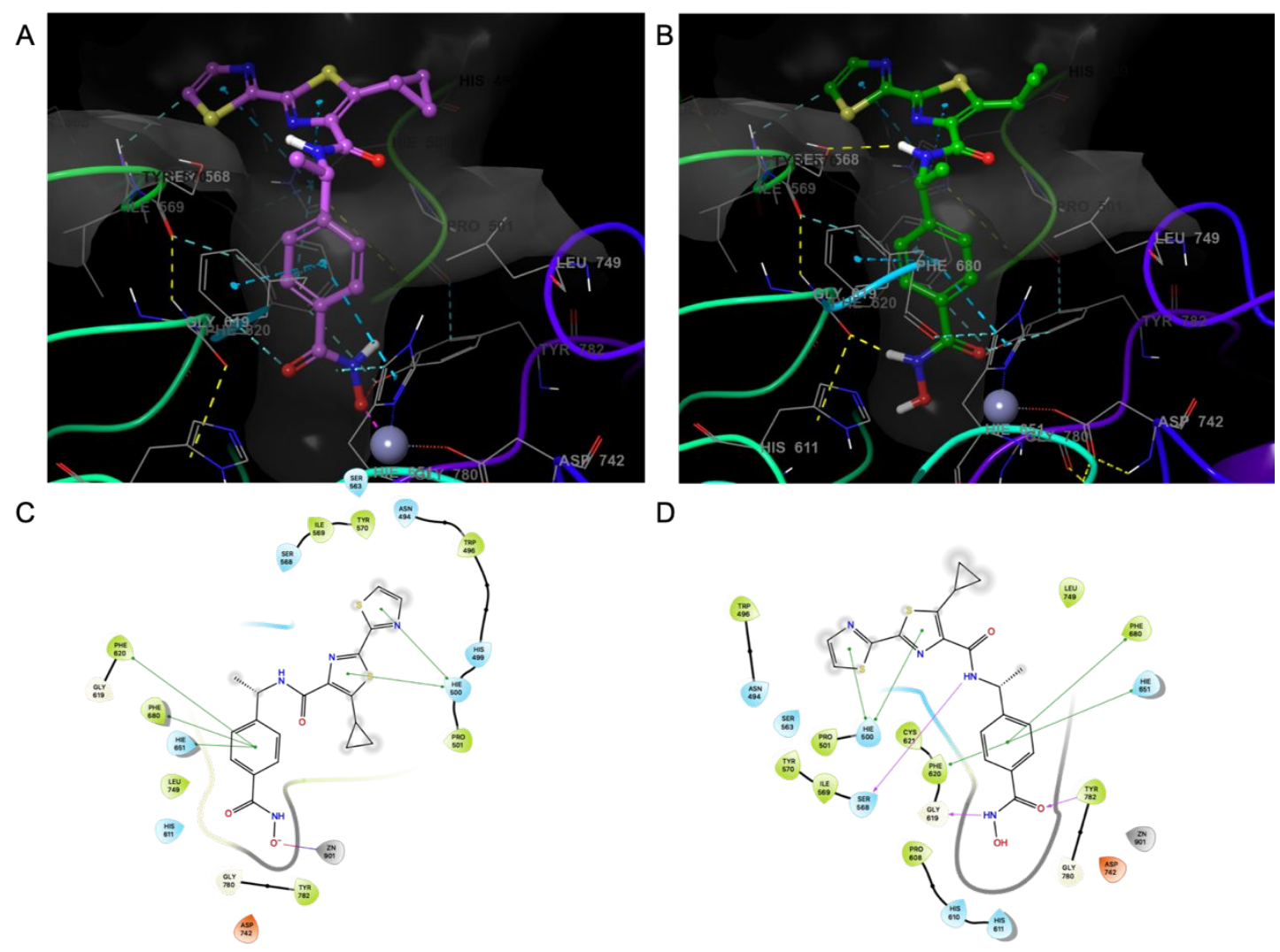

Figure I. Computational modeling/docking studies of H6a (purple, A) and H6b (green, B ) against $h \mathrm{HDAC} 6$ (PDB: $\underline{5 \mathrm{EDU}}$ ), and 2D ligand interaction diagram of H6a (C) and H6b (D). Zinc is shown as a lilac sphere; the surface is shown in gray. Compound atoms are colored as follows: nitrogen, blue; oxygen, red; sulphur ,yellow; hydrogen, white. Ligand-Receptor interaction are colored as follows: hydrogen bond, yellow; $\pi-\pi$ interaction, azure; salt bridge, pink.

\section{Compound H13 Metabolic species variability experiment.}

Comparative Compounds H13 differences in the metabolic processes in human, monkey, canine, rat, and mouse hepatocytes, for the study of animal progeny and safety evaluation.

\section{Materials and Methods}

Mixed primary human hepatocytes (batch 1410194) Xenotech Corporation, USA

Mixed primary cynomolgus hepatocytes (batch 8PRC) RILD company

Mixed primary male Beagle hepatocytes (batch number 1210256) Xenotech 
Corporation, USA

Mixed primary male SD rat hepatocytes (batch number 1210260) Xenotech Corporation, USA

Mixed original Generation of male CD-1 mouse hepatocytes (batch 1310178) Xenotech Corporation, USA

Ammonium acetate (chromatographically pure) ROE Company, USA

Acetonitrile (chromatographically pure) Merck, Germany

Formic acid (chromatographically pure) Fluka, Germany

\section{In vitro metabolism research incubation system}

The total volume of each hatching system is $200 \mu \mathrm{L}$. The medium is William's Medium E medium ( $\mathrm{pH} 7.4)$, including hepatocytes with a cell density of $1.0 \times 10^{6}$ cells $/ \mathrm{mL}$ and a final concentration of $3.0 \mu \mathrm{M}$ at $\mathrm{H} 13,37^{\circ} \mathrm{C}$. After 180 min of reaction, the reaction was stopped by adding $200 \mu \mathrm{L}$ of ice-cold acetonitrile, and the sample was stored at $70{ }^{\circ} \mathrm{C}$ for testing. All incubation were double samples.

\section{Experimental equipment}

Triple TOF $5600^{+}$quadrupole time-of-flight tandem mass spectrometer (Q-TOF MS) with electrospray ionization source (ESI source) and CDS automatic calibration system, AB SCIEX, USA; Acquity UPLC LC system, including two Yuan infusion pump, autosampler, column oven, degasser and TUV UV detector, Waters, USA.

\section{Plasma sample pretreatment method}

The two samples of each hepatocyte incubator were combined and vortexed for $1 \mathrm{~min}$, centrifuged for $5 \mathrm{~min}(14000 \mathrm{rpm})$, the supernatant was taken, transferred to a $10 \mathrm{~mL}$ 
tube, and dried under a nitrogen flow of $40{ }^{\circ} \mathrm{C}$. The residue was 200 . Dissolve $\mu \mathrm{L}$ acetonitrile-water $(10: 90, \mathrm{v} / \mathrm{v})$, centrifuge for $5 \min (14000 \mathrm{rpm})$, and take $7.0 \mu \mathrm{L}$ for UPLC-UV/Q-TOF MS analysis.

\section{Analysis}

Data acquisition with AB Sciex's Analyst ${ }^{\circledR}$ TF V1.6 and Waters' Masslynx V4.1 software, data analysis using AB Sciex's PeakView ${ }^{\circledR}$ V1.2 and MetabolitePilot V1.5 software.

\section{Experiment result}

The results showed that compound H13 was degraded in inactivated hepatocytes and William's Medium E medium with $\mathrm{pH}=7.4$. After incubation for $180 \mathrm{~min}$, the amide bond hydrolysate M2 and a small amount of hydroxylamine reduction product M1 were detected except for the prototype drug.

After incubation of compound H13 in the hepatocyte incubation system for $180 \mathrm{~min}$, methylation and glucose aldehyde were detected in human, monkey, canine and rat hepatocytes except for the prototypic drug M0, the amide hydrolysate M2 and the hydroxylamine reduction product M1. Acid binding to metabolites. The amide bond hydrolyzed metabolite was mainly detected in mouse hepatocytes. Glucuronic acid binding metabolites are higher in human and monkey liver cells. The predicted metabolic pathway of compound H13 in various hepatocytes is shown in Figure II. 


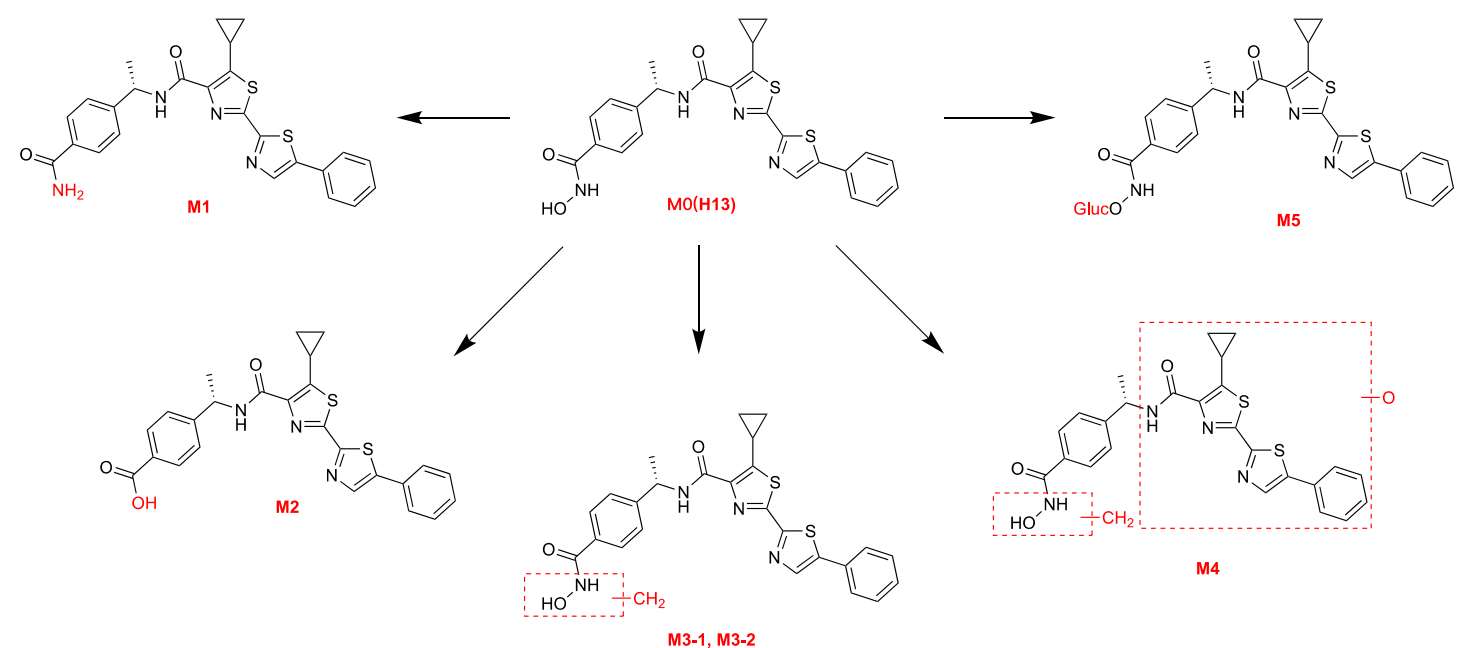

Figure II. Putative compound H13 metabolic pathway in hepatocytes

Compound H13 mainly undergoes glucuronic acid binding and amide bond hydrolytic metabolism in various hepatocytes. Monkey, canine and rat hepatocytes have similar levels of metabolism to human hepatocytes. (Table I) .

Table I. Compound H13 Information on metabolites in various hepatocytes.

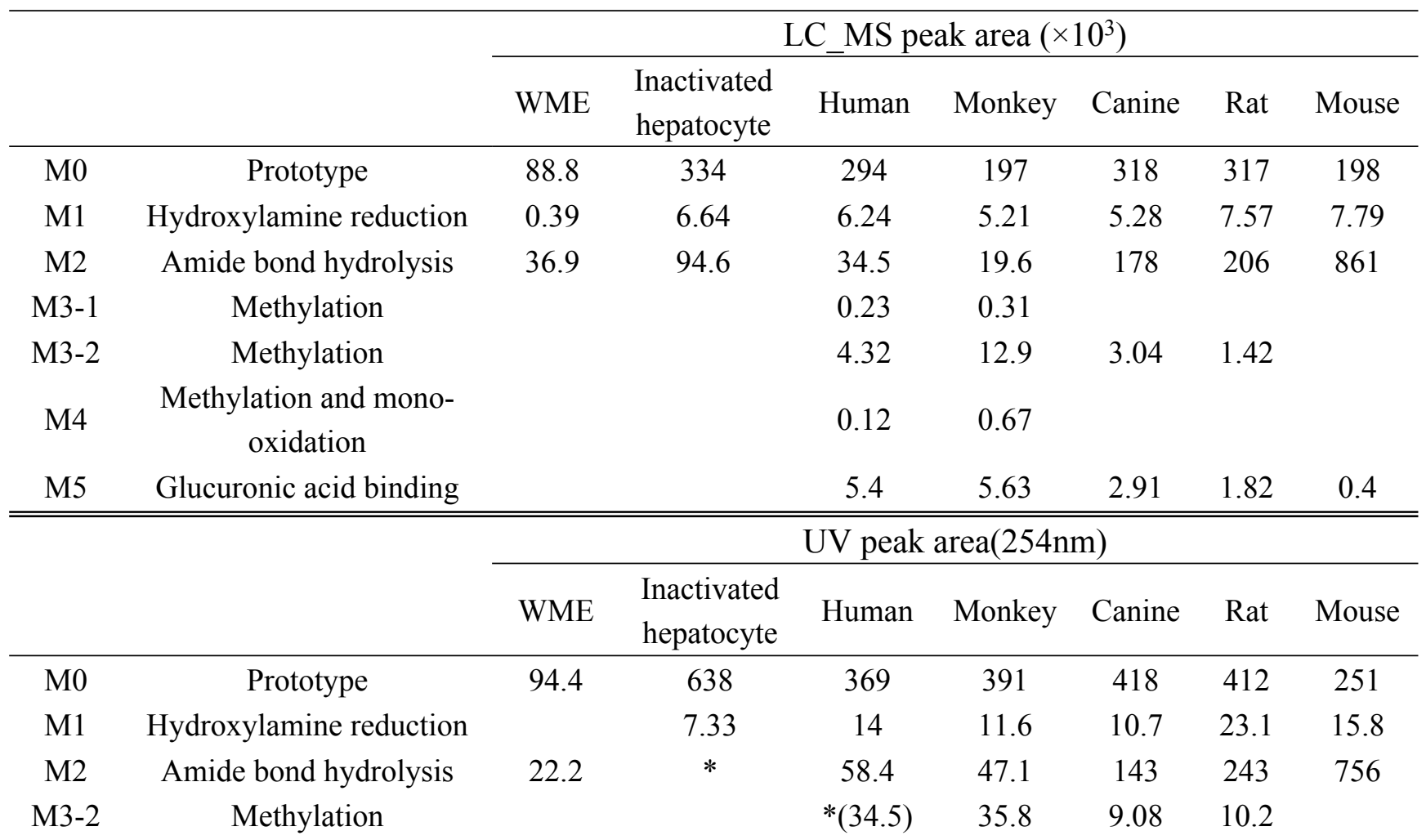


*: Inaccurate integration due to matrix interference 